Chapter 8

\title{
3-D Microvascular Tissue Constructs for Exploring Concurrent Temporal and Spatial Regulation of Postnatal Neovasculogenesis
}

\author{
Mani T. Valarmathi, Stefanie V. Biechler and \\ John W. Fuseler \\ Additional information is available at the end of the chapter \\ http://dx.doi.org/10.5772/53118
}

\section{Introduction}

Development of postnatal new blood vessels occurs essentially by two temporally distinct but interrelated processes, vasculogenesis and angiogenesis. Vasculogenesis is the process of blood vessel formation occurring by a de novo production of endothelial cells in an embryo (primitive vascular network) or a formerly avascular area when endothelial precursor cells (angioblasts, hemangioblasts or stem cells) migrate and differentiate in response to local cues (such as growth factors and extracellular matrix) to form new intact blood vessels (Risau and Flamme, 1995). Angiogenesis refers principally to the sprouting of new blood vessels from the differentiated endothelium of pre-existing vessels. These vascular trees or plexuses are then pruned, remodeled and extended through angiogenesis to become larger caliber vessels (Carmeliet, 2000). In addition, there exists yet another unique mechanism of neovascularization, the postnatal vasculogenesis, where new blood vessels are formed by the process of fusion and differentiation of endothelial progenitors of bone marrow origin (Valarmathi et al., 2009). This indicates a potential role for bone marrow-derived progenitor cells in postnatal neovasculogenesis and/or neoangiogenesis. This implies that additional mechanisms besides angiogenesis can occur in the adult, and has opened up the possibility to investigate the embryonic origin and development of these putative progenitor cells.

The adult bone marrow contains two subsets of multipotential stem cells, hematopoietic stem cells (HSCs) and bone marrow stromal cells or mesenchymal stem cells (BMSCs/ MSCs). BMSCs are a readily available heterogeneous population of cells that can be directed to differentiate into multiple mesenchymal and non-mesenchymal cells either in vitro or in 
vivo (Wakitani et al., 1995; Pittenger et al., 1999; Makino et al., 1999; Fukuda et al., 2001; Bianco et al., 2001; Valarmathi et al., 2009; 2010). Most noticeably, BMSCs have been induced to undergo maturation and differentiation towards vascular endothelial and smooth muscle cell lineages. Previous reports indicate that BMSCs and bone marrow-derived multipotent adult progenitor cells (MAPCs) can be differentiated into endothelial-like cells in vitro and contribute to neoangiogenesis in vivo (Oswald et al., 2004; Reyes et al., 2002; Al-Khaldi et al., 2003). Additionally, it has been shown that BMSCs can augment collateral remodeling and perfusion in ischemic models through paracrine mechanisms rather than by cellular incorporation upon local delivery (Kinnaird et al., 2004). Therefore, the identification of bonemarrow-derived (hematopoietic and non-hematopoietic stem cells) and non-bone-marrowderived (tissue-resident stem/progenitor cells - adipose, neural, heart, skeletal muscle; peripheral and cord blood-derived stem cells) endothelial progenitors cells (EPCs) has led to the realization of potential postnatal vasculogenesis (Urbich and Dimmeler, 2004).

A variety of cellular types can be mobilized from the bone marrow reservoir and can home to sites of neovascularization, where they enhance the angiogenic process (Bertolini et al., 2006). While the concept that vascular progenitors are delivered and recruited was initially conceived and based on the circulating endothelial stem/progenitors (EPCs) paradigm, currently, it has become obvious that other classes of vasculogenic cells can also be derived from the in situ de novo differentiation of precursor cells. Among these, a population of Tie2 expressing mesenchymal precursor cells was recently identified, which are capable of in vitro expansion and of generating Tie 2 negative but $\alpha$-SMA positive cells when re-introduced into the tumors (De Palma et al., 2005). On the one hand, the mechanism by which these cells (EPCs) are recruited from the bone marrow to sites of new blood vessel formation remains an area of active study, but on the other hand, the mechanisms of by which EPCs egress from the bone marrow and subsequent recruitment to sites of neovascularization/ neoangiogenesis warrants further investigation.

Even though there exists ample evidence for the existence of EPCs, proof of a functional requirement for EPCs mobilization and vascular recruitment in human cancer necessitates further experimentation. In addition, to address the temporal as well as spatial contribution of not only these EPCs but also other marrow-derived stem/progenitors to a specific tumor environment require the generation of novel tumor model systems. And these model systems can be utilized to evaluate the subtle contribution of marrow-derived stem/progenitors during the early phases of the neo-angiogenic switch besides oncogenic transformation.

For the above mentioned reasons, embryonic, fetal and postnatal stem cells as well as various types of progenitor cells, can be a potential cellular source for vascular tissue engineering (Levenberg, 2005). However, the source for the early-stage developmental cells is restricted. The utility of embryonic stem cells (ESCs) and induced pluripotent stem cells (iPSCs) in facilitating vascularized tissue/organ regeneration is still in its incipient stages. A number of issues, including a propensity for some implanted ESCs/iPSCs to form benign teratomas and/or malignant teratocarcinomas in the regenerating tissue/organ, remain to be addressed. In contrast to both ESCs/iPSCs, it has been well established that the adult stem cell, BMSCs exhibit multilineage differentiation potential in a well-controlled, predictable 
fashion. Moreover, unlike ESCs derivation, obtaining autologous or allogeneic BMSCs is feasible and can potentially be exploited to develop tissue-engineered blood vessel constructs for therapeutic purposes. Similarly, when compared to bone marrow-derived BMSCs, repeated isolation and rapid expansion of sufficient yield of autologous and/or allogeneic nonbone-marrow-derived resident stem cells/progenitors, especially from vital organs for routine therapeutic purposes are highly constrained. On the contrary, to a certain extent, autologous and/or allogeneic bone marrow-derived BMSCs are amenable for repeated isolation and reasonable in vitro expansion from the patients. In addition, the significant advantage of using these BMSCs is their low immunogenicity. And these autologous or allogeneic BMSCs have been reported to be immunomodulatory and immunotolerogenic both in vitro as well as in vivo. (Aggarwal and Pittenger, 2005). Taken together, these data strongly indicate that BMSCs can represent the potential cell of choice for adult autologous and/or allogeneic stem cell based vascularized tissue regeneration.

Extracellular molecules initiate biological signals and play a critical role in the control of cellular proliferation, differentiation, and morphogenesis. Many parameters, such as the presence and amount of soluble factors such as hormones, growth factors, and cytokines or the insoluble factors such as the physical configuration of the matrix which mediates the cell-cell interactions and cell-matrix interactions, exert a strong influence on the success of angiogenic processes in vitro and presumably in vivo (Even-Ram and Yamada, 2005; Carlson, 2007). The likelihood and ultimate success of in vitro cellular differentiation depends on how closer the cell-matrix interactions and relationships' mimic to those found during normal development or regeneration. In vascular tissue engineering, the application of these principles in vivo will be important to ensure that the matrix/scaffold to be implanted can support endothelial cell proliferation and migration resulting in endothelial tube formation (Ingber and Folkman, 1989). The vital issue for realistic clinical application is whether these scaffolds with preformed network of endothelial capillaries/microvessels can survive implantation into tissue defects and subsequently be able to anastomose to the host vasculature.

We therefore hypothesized that under appropriate in vitro physicochemical microenvironmental cues (combination of growth factors and extra cellular matrix, ECM) multipotent adult BMSCs could be differentiated into vascular endothelial and smooth muscle cell lineages. To test this hypothesis, we characterized the intrinsic vasculogenic differentiation potential of adult BMSCs when seeded onto a three-dimensional (3-D) tubular scaffold engineered from aligned type I collagen strands and cultured in both vasculogenic and nonvasculogenic growth media. In these culture conditions, BMSCs differentiated and matured into both endothelial and smooth muscle/pericyte cell lineages and showed microvascular morphogenesis. We also explored the potential of the 3-D model system to undergo postnatal de novo vasculogenesis.

\section{Experimental approach}

The differentiation of rat BMSCs was carried out on a 3-D tubular scaffold made up of aligned type I collagen-gel fibers. Rat BMSCs were isolated from the tibial and femoral bone 
marrow of adult rats. The BMSCs isolated from the bone marrow were expanded, maintained and passaged to make sure that the attached marrow stromal cells were devoid of any non-adhering populations of cells. Phenotypic characterization of the BMSCs for cell surface markers was performed by confocal microscopy (qualitative evaluation) and singlecolor flow cytometry (quantitative analysis). This adherent population of cells was further purified and enriched by indirect magnetic cell sorting. The cells were subjected to CD90 positive selection. The resultant enriched $\mathrm{CD} 90^{+} / \mathrm{CD} 34^{-} / \mathrm{CD} 45^{-}$fractions were expanded by subculturing and subjected to flow cytometric analysis to validate the proper phenotype. This population of purified BMSCs was used in all experiments. For vasculogenic differentiation of BMSCs, the expanded and purified population of $\mathrm{CD} 90^{+} \mathrm{BMSC}$ were seeded into the collagen-gel tubular scaffold and cultured either in vasculogenic or non-vasculogenic culture medium for 28 days. At regular intervals of 7, 14, 21 and 28 days the tube cultures were assayed by RT-qPCR, immunofluorescence, ultrastructural and biochemical analyses for various endothelial and smooth muscle differentiation markers as shown in table 1, 2 and 3. The time points at which these analyses were carried out cover the optimal range of both vasculogenesis and angiogenic processes seen in vivo and/or in vitro and mimic the progression of microvascular development.

\section{Research methods}

\subsection{Fabrication of tubular scaffold}

The 3-D collagen type I tube served as a scaffold on which rat BMSCs differentiation cultures were carried out (Figure 1). The details of the production and properties of the collagen tubular scaffolds have previously been described (Yost et al., 2004). Briefly, a 25 $\mathrm{mg} / \mathrm{ml}$ solution of bovine collagen type I was extruded with a device that contained two counter-rotating cones. The liquid collagen was fed between the two cones and forced through a circular annulus in the presence of an $\mathrm{NH}_{3}$-air $(50-50 \mathrm{vol} / \mathrm{vol})$ chamber. This process results in a hollow cylindrical tube of aligned collagen fibrils with an inner central lumen. The dimensions of tubes produced for this set of experiments had a length of $30 \mathrm{~mm}$ with a luminal diameter of $4 \mathrm{~mm}$ and an external diameter of $5 \mathrm{~mm}$, leaving a wall thickness of $0.5 \mathrm{~mm}$. The collagen tubes had a defined fiber angle of $18^{\circ}$ relative to the central axis of the tube and had pores ranging from 1 to $10 \mu \mathrm{m}$. The rationale for the particular orientation of collagen fibers was based on our previous work on cardiovascular tissue engineering (Yost et al., 2004). When proepicardial organ (PE) cells were seeded onto this scaffold, they underwent maturation and differentiation and produced elongated vessel-like structures reminiscent of in vivo-like phenotype (Valarmathi et al., 2008). The tubes were sterilized using gamma radiation $1200 \mathrm{~Gy}$ followed by Stratalinker UV crosslinker 1800 (Stratagene) and then placed in Mosconas's solution (in mM: 136.8 $\mathrm{NaCl}, 28.6 \mathrm{KCl}, 11.9 \mathrm{NaHCO}_{3}, 9.4$ glucose, $0.08 \mathrm{NaH}_{2} \mathrm{PO}_{4}, \mathrm{pH} 7.4$ ) (Sigma-Aldrich) containing $1 \mu \mathrm{l} / \mathrm{ml}$ gentamicin (Sigma-Aldrich) and incubated in $5 \% \mathrm{CO}_{2}$ at $37^{\circ} \mathrm{C}$ until cellular seeding (Valarmathi et al., 2010). 

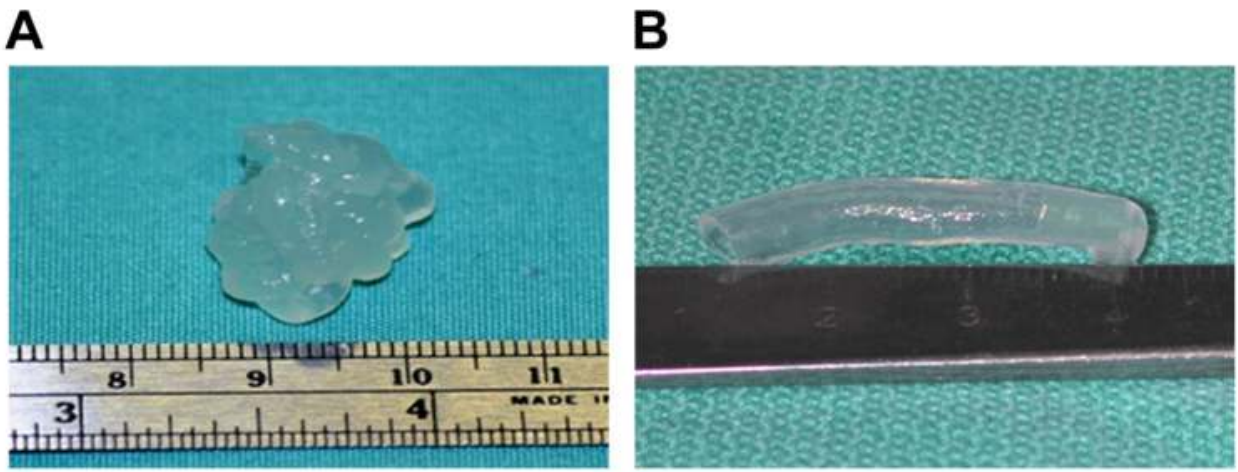

Figure 1. Fabrication of 3-D collagen gel based tubular scaffolds engineered from aligned type I collagen fibers. Type I collagen was extracted from bovine calf hides (A). Bovine collagen type I was extruded with a device that contained two counter-rotating cones to generate the 3-D collagen gel tubular scaffolds. The dimensions of tubes produced for this set of experiments had a length of $30 \mathrm{~mm}$ with a luminal diameter of $4 \mathrm{~mm}$ and an external diameter of $5 \mathrm{~mm}$, leaving a wall thickness of $0.5 \mathrm{~mm}$. The collagen tubes had a defined fiber angle of $18^{\circ}$ relative to the central axis of the tube and had pores ranging from 1 to $10 \mu \mathrm{m}$ (B). (A and B, courtesy of M.J. Yost)

\subsection{BMSCs isolation, expansion and maintenance}

The initial step is to isolate the mononuclear cells from the bone marrow by aspiration and centrifugation followed by plating and isolation of the cells based on differential adherence capacity to tissue culture dishes (passage 0 cells). Rat BMSCs were isolated from the bone marrow of adult 300g Sprague Dawley ${ }^{\circledR M}$ SD®TM rats (Harlan Sprague Dawley, Inc.). Briefly, after deep anesthesia, the femoral and tibial bones were removed aseptically and cleaned extensively to remove associated soft connective tissues. The marrow cavities of these bones were flushed with Dulbecco's Modified Eagle Medium (DMEM; Invitrogen) and combined. The isolated marrow plugs were triturated, and passed through needles of decreasing gauge (from 18 gauge to 22 gauge) to break up clumps and cellular aggregates. The resulting single-cell suspensions were centrifuged at $200 \mathrm{~g}$ for 5 minutes. Nucleated cells were counted using a Neubauer chamber. Cells were plated at a density of $5 \times 10^{6}-2 \times 10^{7}$ cells per T75 $\mathrm{cm}^{2}$ flasks in basal media composed of DMEM supplemented with $10 \%$ fetal bovine serum (FBS, lot-selected; Hyclone), gentamicin $(50 \mu \mathrm{g} / \mathrm{ml})$ and amphotericin B $(250 \mathrm{ng} / \mathrm{ml})$ and incubated in a humidified atmosphere of $5 \% \mathrm{CO}_{2}$ at $37^{\circ} \mathrm{C}$ for 7 days. The medium was replaced, and changed three times per week until the cultures become $70 \%$ confluent (between 12 and 14 days). Cells were trypsinized using $0.05 \%$ trypsin- $0.1 \%$ EDTA and re-plated at a density of $1 \times 10^{6}$ cells per T75 $\mathrm{cm}^{2}$ flasks. After three passages, attached marrow stromal cells were devoid of any non-adhering population of cells. These passaged BMSCs were cryopreserved and stored in liquid nitrogen until further use (Valarmathi et al., 2011). 


\subsection{Immunophenotyping of BMSCs by flow cytometry and confocal microscopy}

BMSCs are a heterogeneous population of cells with varying degrees of cell shapes and sizes (Anokhina et al., 2007). Stringent characterization of BMSCs used in experimental procedures is required for various cell surface markers; this is to ensure that the employed population of cells contains solely stem/progenitor cells. This will obviate the possible contamination of marrow-derived endothelial cells and macrophages that are part of the adherent population of cultured cells. Therefore, characterization of BMSCs included qualitative evaluation for various cell surface markers and was performed on cells grown in the Lab-tek $^{\mathrm{TM}}$ chamber slide system ${ }^{\mathrm{TM}}$ (Nunc) using a Zeiss LSM 510 Meta confocal scanning laser microscope (Carl Zeiss, Inc.), and quantitative analysis of the same set of markers was performed by single-color flow cytometry using a Coulter ${ }^{\circledR}$ EPICS® ${ }^{\circledR} \mathrm{LL}^{\mathrm{TM}}$ Flow Cytometer (Beckman Coulter, Inc.) as previously described (Valarmathi et al., 2009).

\begin{tabular}{|c|c|c|c|}
\hline \multicolumn{4}{|c|}{ Criteria to Identify BMSCs/MSCs } \\
\hline 1. & Adherence to plastic in standard culture conditions & & \\
\hline \multirow[t]{6}{*}{2.} & Phenotype & Positive $(\geq 95 \%+)$ & Negative $(\leq 2 \%+)$ \\
\hline & & CD73 & CD11b or CD14 \\
\hline & & CD90 & CD34 \\
\hline & & CD105 & $\mathrm{CD} 45$ \\
\hline & & & CD79a or CD19 \\
\hline & & & HLA-DR \\
\hline
\end{tabular}

3. In vitro differentiation: Osteoblasts, Chondroblasts and Adipocytes.

(Demonstrated by staining of in vitro cell culture)

International Society for Cellular Therapy (ISCT): Mesenchymal and Tissue Stem Cell Committee

Table 1. Criteria to identify BMSCs/MSCs (Dominici et al., 2006)

Immunophenotyping of passage 3 undifferentiated BMSCs for various cell surface markers by flow cytometry revealed that the fluorescent intensity and distribution of the cells stained for CD11b, CD31, CD34, CD44, CD45 and CD106 were not significantly different from the intensity and distribution of cells stained with isotype controls (Figure 2 A-E, $\mathrm{H})$. In addition, these cells were negative for the rat endothelial cell surface marker OX43 (Figure 2, I), an antigen expressed on all vascular endothelial cells of rat, indicating that these cultures were devoid of any possible hematopoietic stem and/or progenitor cells as well as differentiated bone-marrow-derived endothelial cells. In contrast, BMSCs exhibited high expression of CD73 and CD90 surface antigens (Figure 2, F-G), which is consistent with their undifferentiated state. Furthermore, flow cytometric analysis of the same passage 3 BMSCs for various other vascular endothelial cell surface antigens and smooth muscle cell intracellular antigens revealed that these cells were negative for Flt1, Flk1 and VE-cadherin (Figure 2, J-L) and, were predominantly positive for calponin (Figure 2, $\mathrm{M})$. The expression profiles of these surface molecules were consistent with previous re- 
ports and the minimal criteria for defining multipotent mesenchymal stromal cells, enunciated by the international society for cellular therapy (ISCT) position statement (Valarmathi et al., 2009; Reyes et al., 2002; Dominici et al., 2006).

Phenotypic characterization using the same set of markers on passage 3 BMSCs by confocal microscopy also revealed that the cells were negative for CD11b, CD31, CD34, CD44, CD45 and OX43 (Figure 3, A-J, O-P), and strongly positive for CD73 and CD90 (Figure 3, K-N). The permeabilized cells when stained for Vcam1 (CD106), Flt1 (Vegfr1), Flk1 (Vegfr2) and VE-cadherin (Figure 4, A-H) revealed faintly detectable cytoplasmic and/or nuclear signal of these endothelial antigens. While these cells showed abundant cytoplasmic expression of smooth muscle antigen, calponin (Figure 4, I-J). Phenotypic characterization and evaluation of these markers on clonally expanded BMSCs showed similar expression patterns consistent with their parent culture.

\begin{tabular}{|c|c|c|c|}
\hline Primary Antibodies & Dilutions & Source & Cell Target \\
\hline \multicolumn{4}{|c|}{ BMSCs characterization markers } \\
\hline CD11b & $1: 50$ & BD Pharmingen & Leukocytes \\
\hline CD31 & $1: 10$ & Abcam & Endothelial \\
\hline CD44 & $1: 10$ & Gene Tex, Inc & Leukocytes \\
\hline CD45 & $1: 50$ & BD Pharmingen & Hematopoietic \\
\hline CD73 & $1: 50$ & BD Pharmingen & BMSCS \\
\hline CD90 & $1: 50$ & BD Pharmingen & BMSCs \\
\hline CD106 & $1: 50$ & BD Pharmingen & Endothelial \\
\hline OX43 & $1: 10$ & Gene Tex, Inc & Endothelial \\
\hline \multicolumn{4}{|c|}{ Endothelial cell differentiation markers } \\
\hline CD34 & $1: 100$ & Santa Cruz Biotechnology & Endothelial \\
\hline Flt-1 & $1: 100$ & Santa Cruz Biotechnology & Endothelial \\
\hline Flk-1 & $1: 100$ & Santa Cruz Biotechnology & Endothelial \\
\hline VE-cadherin & $1: 100$ & Santa Cruz Biotechnology & Endothelial \\
\hline Pecam 1 & $1: 100$ & Santa Cruz Biotechnology & Endothelial \\
\hline Vwf & $1: 100$ & Santa Cruz Biotechnology & Endothelial \\
\hline Tomato lectin & $1: 50$ & Vector Laboratories & Endothelial \\
\hline Fibronectin & $1: 200$ & Abcam & Endothelial \\
\hline \multicolumn{4}{|c|}{ Smooth muscle cell differentiation markers } \\
\hline a-SMA & $1: 100$ & Sigma-Aldrich & Smooth Muscle \\
\hline Calponin & $1: 5000$ & Sigma-Aldrich & Smooth Muscle \\
\hline
\end{tabular}

Table 2. Primary antibodies used in this study (Valarmathi et al., 2009). 

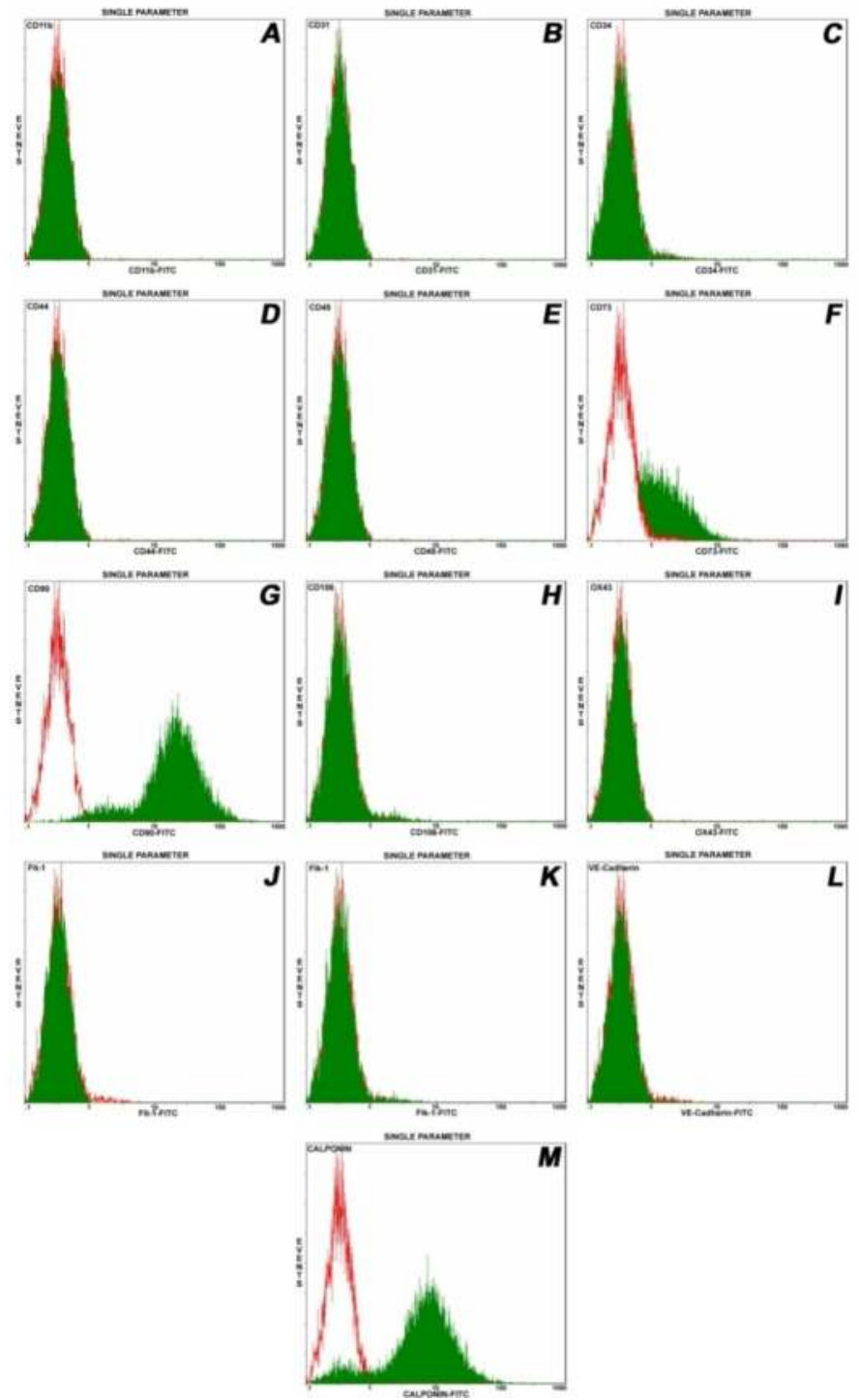

Figure 2. Immunophenotyping of passage 3 undifferentiated rat BMSCs by flow cytometry. Single parameter histograms showing the relative fluorescence intensity of staining (abscissa) and the number of cells analyzed, events (ordinate). Isotype controls were included in each experiment to identify the level of background fluorescence. The intensity and distribution of cells stained for hematopoietic and endothelial markers; CD11b, CD31, CD34, CD44, CD45, CD106, OX43, Flt-1, Flk-1 and VE-cadherin (green, shaded peaks) were not significantly different from those of isotype control (red, open peaks) (Panels A-E, H-L). The fluorescent intensity was greater (shifted to right) when BMSCs were stained with CD73, CD90 and calponin (green) compared to isotype control (red) (Panels F, G, M). The predominant population of BMSCs uniformly expressed CD90 surface molecule, consistent with their undifferentiated state. Adapted from Valarmathi et al., 2009. 

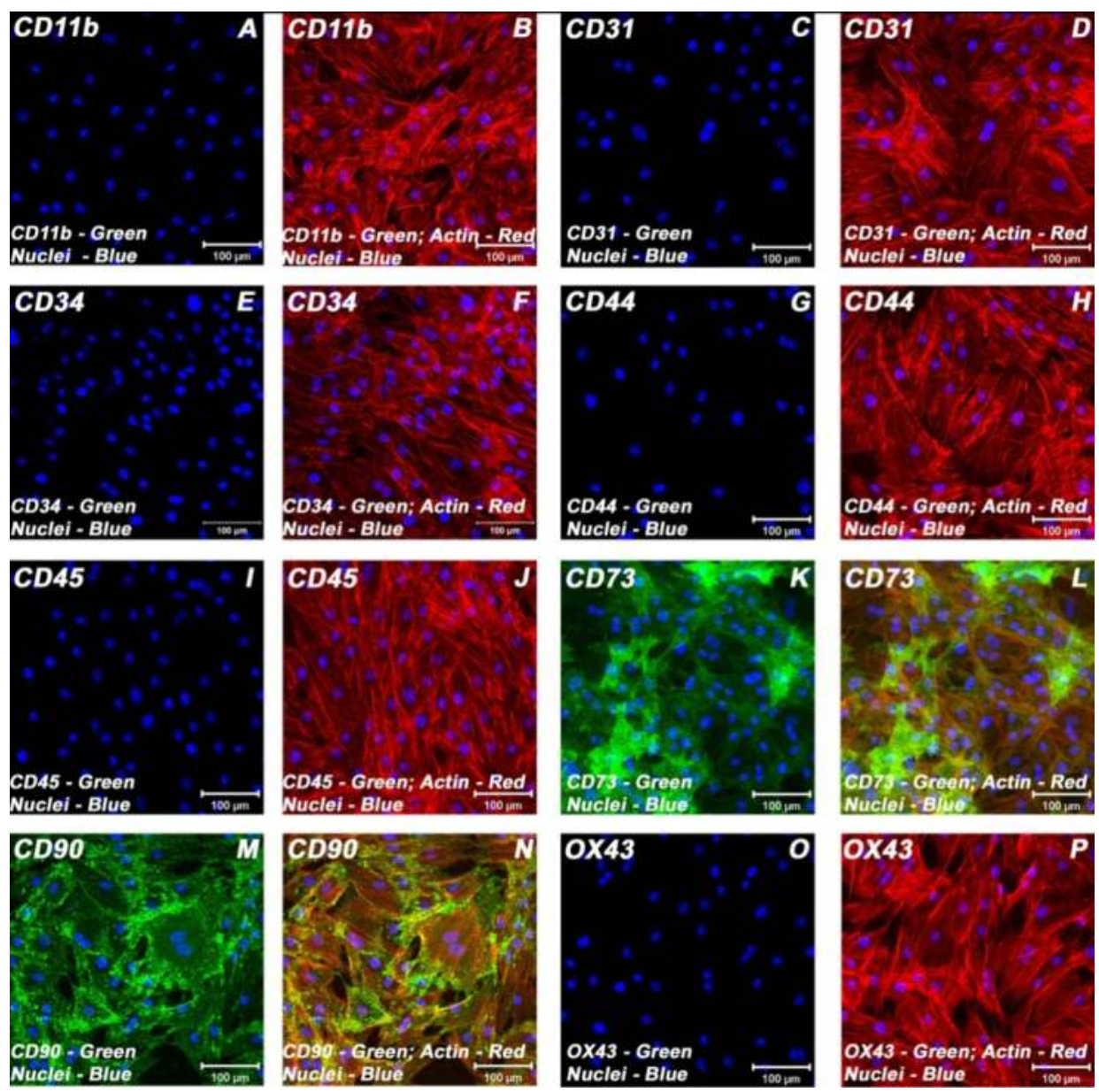

Figure 3. Immunophenotyping of passage 3 undifferentiated rat BMSCs by confocal microscopy. Phenotypic characterization and evaluation revealed that the permeabilized cells were negative for CD11b, CD31, CD34, CD44, CD45 and OX43 (Figure 3, A-J, O-P), indicating that these cultures were devoid of any potential hematopoietic and/or endothelial cells of bone marrow origin. However, the cells consistently expressed both CD73 and CD90 (Figure3, K-N) surface antigens, a property of mesenchymal/stromal stem cells. Isotype controls were included in each experiment to identify the level of background staining. Cells were also stained for nuclei (blue, DAPI) and fibrillar actin (red, rhodamine phalloidin). Merged images (B, D, F, H, J-N, P). (A-P, scale bar $100 \mu \mathrm{m}$ ). Adapted from Valarmathi et al., 2009. 

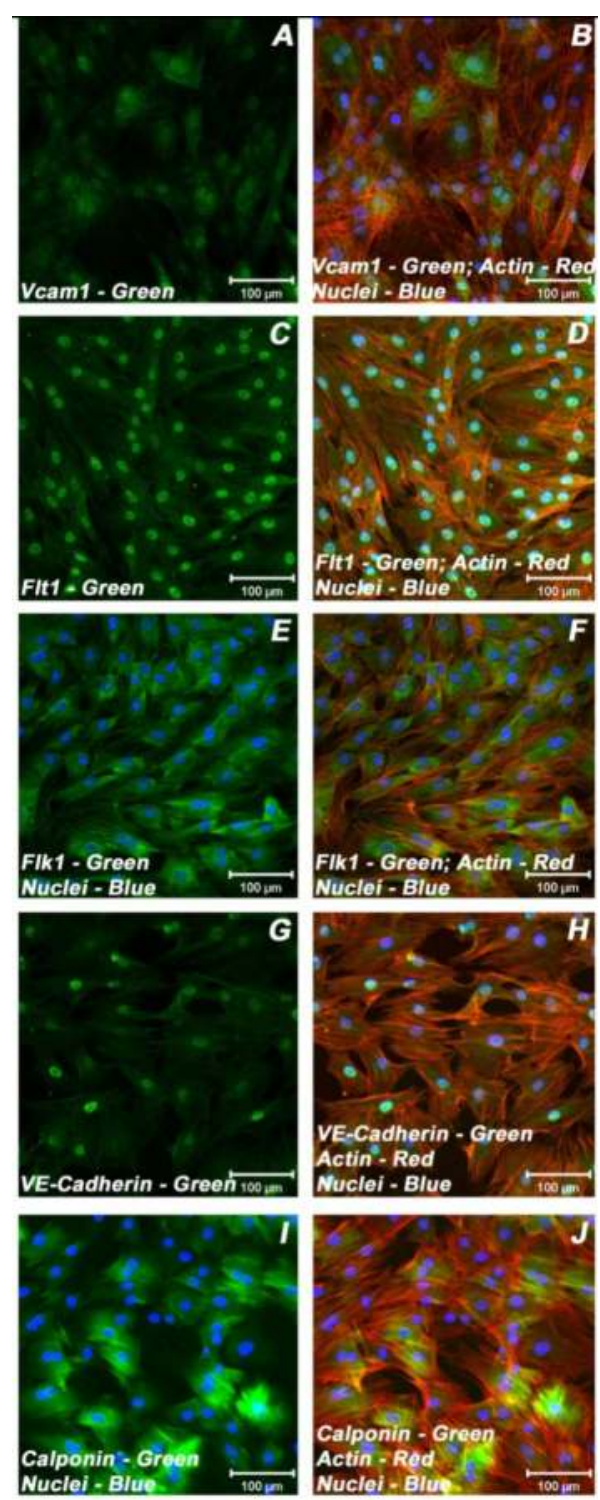

Figure 4. Confocal microscopic analysis of various vascular related antigens on passage 3 undifferentiated rat BMSCs. Evaluation of the permeabilized cells for Vcam1 (CD106), Flt1 (Vegfr1), Flk1 (Vegfr2) and VE-cadherin revealed faintly detectable cytoplasmic and/or nuclear signals of these endothelial antigens (Figure 4, A-H). Whereas, these cells showed abundant cytoplasmic expression of smooth muscle antigen, calponin (Figure 4, I-J). Suggesting that BMSCs constitutively express very low-levels of endothelial associated antigens as well as very high-levels of smooth muscle specific antigens. Isotype and/or negative controls were included in each experiment to identify the level of background staining. Cells were also stained for nuclei (blue, DAPI) and fibrillar actin (red, rhodamine phalloidin). Merged images (B, D-F, H-J). (A-J, scale bar $100 \mu \mathrm{m})$. Adapted from Valarmathi et al., 2009. 


\subsection{Purification and enrichment of $\mathrm{CD}^{+} 0^{+} \mathrm{BMSC}$ by Magnetic-Activated Cell Sorting (MACS)}

Purification and enrichment of input BMSCs (such as CD45-, CD34-, CD105) are mandatory either using MACS (magnetic activated cell sorter) or FACS (fluorescent activated cell sorter). Since the unpurified fraction may contain sizable number of contaminating adherent macrophages and bone marrow-derived endothelial progenitors and differentiated endothelial cells. The adherent populations of BMSCs were further purified by indirect magnetic cell labeling method using an autoMACS ${ }^{\mathrm{TM}}$ Pro Separator (Miltenyi Biotech). The cells were subjected to CD90 positive selection by incubating the cells with FITC- labeled anti-CD90 antibodies (BD Pharmingen), followed by incubation with antiFITC magnetic microbeads (Miltenyi Biotech), and passed through the magnetic columns as per the manufacturer's instructions. The resultant enriched CD90 $/$ CD $34-\mathrm{CD}^{-} 5^{-}$fractions were expanded by subcultivation and subjected to flow cytometric analysis as described previously (Valarmathi et al., 2010).

\subsection{BMSCs vasculogenic differentiation}

For vasculogenic differentiation of BMSCs, the purified population of $\mathrm{CD}^{+} 0^{+} \mathrm{BMSC}$ were seeded into the collagen-gel tubes at a density of $0.5 \times 10^{6}$ cells $/ 30 \mathrm{~mm}$ tube lengths and cultured either in mesenchymal stem cell growth medium supplemented with $10 \%$ FBS, penicillin and streptomycin (Poietics ${ }^{\circledR}$ MSCGM $^{\mathrm{TM}}$ BulletKit ${ }^{\circledR}$; Lonza Ltd.) or microvascular endothelial cell growth medium (Clonetics ${ }^{\circledast}$ EGM $^{\circledR}$-MV Bullet Kit ${ }^{\circledR}$; Lonza Ltd.) supplemented with 5\% FBS, bovine brain extract, human epidermal growth factor (hEGF), hydrocortisone, amphotericin B and gentamicin for 28 days. These BMSCs seeded tubes were cultured either in vasculogenic or non-vasculogenic medium for the defined time periods of 7, 14, 21 and 28 days. In addition, BMSCs were seeded in $65-\mathrm{mm}$ Petri dishes at a density of $3 \times 10^{3}$ cells $/ \mathrm{cm}^{2}$ and cultured in non-vasculogenic (MSCGM) or vasculogenic (EGMMV) media for $7,14,21$ and 28 days.

\section{BMSCs based postnatal de novo vasculogenesis and in situ vascular regeneration}

The 3-D collagen-gel tubular scaffold has previously been used to create models of vascularized bone development (Valarmathi et al., 2008a; 2008b). Here we report the utility of a 3-D tubular construct for its ability to support the vasculogenic differentiation of BMSCs culminating into microvascular structures, which are similar to those structures resulting from postnatal de novo vasculogenesis and angiogenesis (Valarmathi et al., 2008a; 2008b).

In the developing vertebrate embryo, the initial event of blood vessel formation is the differentiation of vascular endothelial cells, which subsequently cover the entire interior surface of all blood vessels. Angioblasts are a subpopulation of primitive mesodermal cells that are committed to differentiate into endothelial cells and later on form the primitive vascular lab- 
yrinth (Risau and Flamme, 2000). In addition, endothelial cells can also arise from hemangioblasts, a common precursor for both hematopoietic and endothelial cells (His et al., 1900).

In adults, endothelial precursor cells have been identified in bone marrow, peripheral blood and blood vessels (Prater et al., 2007). Two subsets of multipotential stem cells, HSCs and BMSCs/MSCs are resident in the postnatal bone marrow. Of these cells, BMSCs can be differentiated into osteoblasts, chondrocytes, adipocytes, smooth muscle cells and hematopoietic supportive stroma either in vitro or in vivo (Bianco et al., 2001). Previous studies have provided substantial evidence that bone-marrow-derived stem and/or progenitor cells can be differentiated into either endothelial or smooth muscle cells in vitro and in pathological situations are capable of contributing to neoangiogenesis in vivo by cellular integration (Carmeliet and Luttun, 2001).

Although there are a plethora of studies focused on developing viable scaffolds for osteogenic, chondrogenic, adipogenic and musculogenic differentiation of BMSCs (Lanza et al., 2000), the optimal scaffolds that are capable of inducing and supporting the growth and differentiation of BMSCs into vascular cell lineages are yet to be identified and characterized. Despite the much known vasculogenic potential and transgermal plasticity of BMSCs; none of these studies explicitly demonstrated the postnatal de novo vasculogenic potential of BMSCs in vitro (Reyes et al., 2002; Oswald et al., 2004; Brey et al., 2005).

When compared to 2-D planar cultures, the potential 3-D models of vasculogenesis allow us to understand the role of specific factors under more physiological and spatial conditions with respect to dimensionality, architecture and cell polarity. Nevertheless, the molecular composition and the natural complexity and diversity of in vivo extra cellular matrix (ECM) organization cannot be easily mimicked or reproduced in vitro (Vailhe et al., 2001). In addition, even though quite a few in vitro 3-D models of vasculogenesis based on fibrin and collagen gels are in vogue (Folkman and Haudenschild, 1980); none have explored the behavior of BMSCs and their intrinsic vasculogenic differentiation potential on a topographically structured 3-D tubular scaffold made of uniformly aligned type I collagen fibers.

Previous studies demonstrated that the formation of endothelial tubes in vitro was largely influenced by the nature of the substrate (Kleinman et al., 1982). The formation of endothelium lined tubular structures was enhanced when the substrate was rich in laminin (Madri et al., 1988), whereas a matrix rich in type I collagen would not promote rapid tubulogenesis (Montesano et al., 1983; Ingber and Folkman, 1989). Similarly, Ingber and Folkman (1989) documented that under a given cocktail of growth factors, the local physical nature of the interaction between endothelial cells and the underlying matrix/substrate ultimately determined the tubular morphogenesis. Substrates containing abundant fibronectin promoted adhesion, spreading and growth of endothelial cells. In contrast, less adhesive substrate or matrix materials that were arranged three-dimensionally permitted the endothelial cells to retract and form tubes (Ingber and Folkman, 1989).

In general, successful in vitro differentiation of cells depends on cell-cell as well as cell-matrix interactions. Therefore, we hypothesized that under appropriate in vitro local environmental cues (combination of growth factors and ECM) multipotent postnatal BMSCs could 
be induced to undergo microvascular development. Hence, we developed a 3-D culture system in which a pure population of $\mathrm{CD}^{+} 0^{+}$rat BMSCs was seeded and cultured on a highly aligned, porous, biocompatible collagen-fiber tubular scaffold for differentiation purposes. Here, we utilized two types of growth media for vasculogenic differentiation purpose, MSCGM (non-vasculogenic) as control and EGMMV (vasculogenic) preferentially for microvascular differentiation. Both of these culture media consistently promoted the vasculogenic differentiation of BMSCs and also supported the formation of endothelium lined vessel-like structures within the constructs.

A number of early and late stage markers associated with rodent vascular development in vivo were used in this study to characterize the rat BMSCs derived microvascular structures at mRNA and protein levels, which included: CD31/Pecam1, Flt1 (Vegfr1), Flk1 (Vegfr2/ Kdr), VE-cadherin (CD144), CD34, Tie1, Tek (Tie2), and Von Willibrand factor (Vwf). Platelet/endothelial cell adhesion molecule, also known as CD31, is a transmembrane protein expressed abundantly early in vascular development that may mediate leukocyte adhesion and migration, angiogenesis, and thrombosis (Albelda et al., 1991). The other early stage differentiation markers Flk1 and Flt1 that are receptors for the vascular endothelial cell growth factor-A (Vegf) essentially play a vital role in embryonic vascular and hematopoietic development (Shalaby et al., 1997). Similarly, VE-cadherin, a member of the cadherin family of adhesion receptors, is a specific and constitutive marker of endothelial cell plays an important role in early vascular assembly. Vascular markers that are expressed at a later stage include CD34 and Tie-2 (Bautch et al., 2000). CD34 is a transmembrane surface glycoprotein that is expressed in endothelial cells and hematopoietic stem cells. Tie1 and Tek are receptor kinases on endothelial cells that are essential for vascular development and remodeling in the embryo and may also mediate maintenance and repair of the adult vascular system. In late phases of vasculogenesis, the mature endothelial cells will synthesize and secrete Vwf homolog, a plasma protein that mediates platelet adhesion to damaged blood vessels and stabilizes blood coagulation factor VIII.

\begin{tabular}{|c|c|c|c|c|c|}
\hline Genes & Forward primer & Reverse primer & $\begin{array}{l}\text { Product } \\
\text { length } \\
\text { (bp) }\end{array}$ & $\begin{array}{l}\text { Annealing } \\
\text { temperature } \\
\left({ }^{\circ} \mathrm{C}\right)\end{array}$ & $\begin{array}{l}\text { GenBank accession } \\
\text { No }\end{array}$ \\
\hline Pecam1 & $5^{\prime}$-CGAAATCTAGGCCTCAGCAC-3' & 5'-CTTTTTGTCCACGGTCACCT-3' & 227 & 56 & NM_03159.1 \\
\hline $\mathrm{Kdr}$ & 5'-TAGCGGGATGAAATCTTTGG-3' & 5'-TTGGTGAGGATGACCGTGTA-3' & 207 & 56 & NM_013062.1 \\
\hline Tie1 & 5'-AAGGTCACACACACGGTGAA-3' & 5'-TGGTGGCTGTACATTTTGGA-3' & 174 & 56 & XM_233462.4 \\
\hline Tek & 5'-CCGTGCTGCTGAACAACTTA-3' & 5'-AATAGCCGTCCACGATTGTC-3' & 201 & 56 & NM_001105737.1 \\
\hline Vwf & $5^{\prime}-$ GCTCCAGCAAGTTGAAGACC-3' & 5'-GCAAGTCACTGTGTGGCACT-3' & 163 & 56 & XM_342759.3 \\
\hline Gapdh & 5'-TTCAATGGCACAGTCAAGGC-3' & 5'-TCACCCCATTTGATGTTAGCG-3' & 101 & 56 & XR_007416.1 \\
\hline
\end{tabular}

Table 3. RT-qPCR primer sequences used in this study (Valarmathi et al., 2009; Rozen and Skaletsky, 2000). 
In any type of in vitro cellular differentiation, the cytodifferentiated cells need to be critically evaluated for their maturation and differentiation at transcriptional, translational and functional levels. Therefore, to study the expression pattern of key vasculogenic gene transcripts in the 3-D tube constructs; we examined the time-dependent expression pattern of Pecam1, Kdr, Tie1, Tek and Vwf at mRNA level in the tube constructs by real-time PCR (Figure 5 A-D).
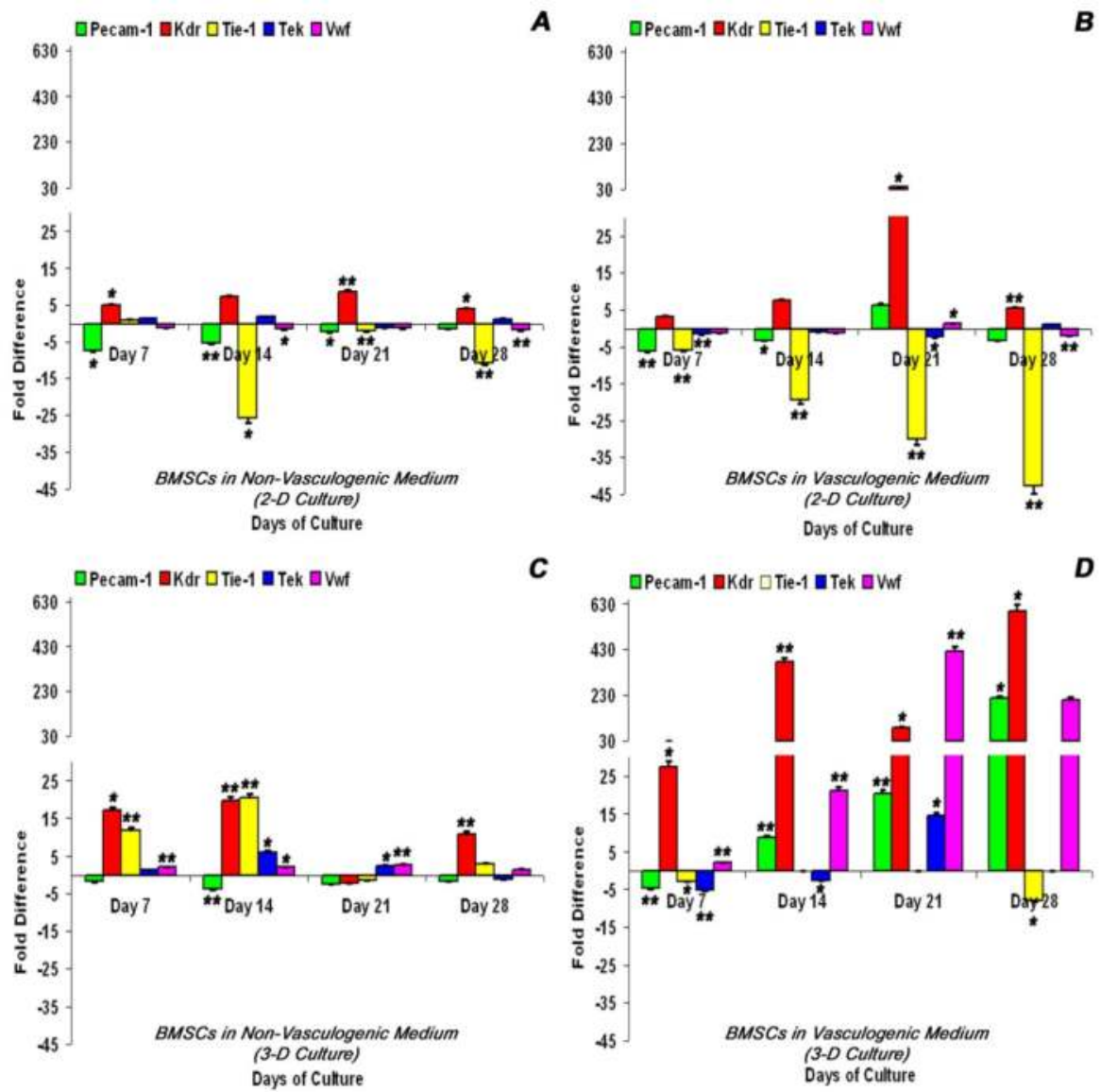

Figure 5. Real-time reverse transcriptase quantitative polymerase chain reaction (RT-qPCR) analysis of various key vasculogenic markers, platelet/endothelial cell adhesion molecule 1 (Pecam1), kinase insert domain protein receptor (Kdr/Flk1/Vegfr-2), tyrosine kinase with immunoglobulin-like and EGF-like domains 1 (Tie1), endothelial-specific receptor tyrosine kinase (Tek/Tie2) and Von Willebrand factor homology (Vwf) as a function of time (abscissa). BMSCs cultured in Petri dishes (2-D culture) in mesenchymal stem cell growth medium (A) and, in microvascular growth medium (B). BMSCs cultured in collagen-gel tubular scaffolds (3-D culture) in mesenchymal stem cell growth medium (C) and, in microvascular growth medium (D). The calibrator control included passage 4 BMSCs day 0 sample and; the target gene expression was normalized by a non-regulated reference gene expression, Gapdh. The expression ratio (ordinate) was calculated using the REST-XL version 2 software (Pfaffl 2001; Pfaffl et al., 2002). The values are means \pm standard errors for three cultures $(n=3),{ }^{*} p<0.005 ;{ }^{* *} P<0.001$. Adapted from Valarmathi et al., 2009. 
Constitutive expressions of these markers were detected at low to very low levels in undifferentiated BMSCs. RT-qPCR results showed that differentiation of BMSCs under vasculogenic culture conditions for 28 days resulted in increased expression of transcripts coding for various endothelial cell associated proteins such as Pecam1, Kdr, Tek and Vwf. The peak expression of $\mathrm{Vwf}$, the endothelial specific protein occurred around day 21 (over 400 fold) indicating that the differentiating cells acquired a distinctive phenotype and biosynthetic activity of differentiated and matured endothelial cells. The upregulation of Tek during this period may represent the continual development and remodeling of the developing microvessels. Whereas differentiation of BMSCs under non-vasculogenic conditions for 14 days showed signs of early and rapid induction of transcripts coding for both early and late stage endothelial cell markers such as Kdr, Tie1, Tek and Vwf. The peak expression of Vwf occurred during day 14 (over 20 fold).

As revealed by immunostaining for various vasculogenic markers, day 21 vasculogenic and non-vasculogenic tube cultures showed that BMSCs were able to adhere, proliferate, migrate and, undergo complete maturation and differentiation into microvascular structures (Figure 6 A-C). BMSCs derived microvessel formation is a combination of de novo vasculogenesis i.e., in situ endothelial cell differentiation and endothelium-lined tube formation, and angiogenesis, endothelial sprouting from existing endothelial tubes. In addition, these microvessels are stabilized by association with BMSC-derived smooth muscle cells and/or pericytes.
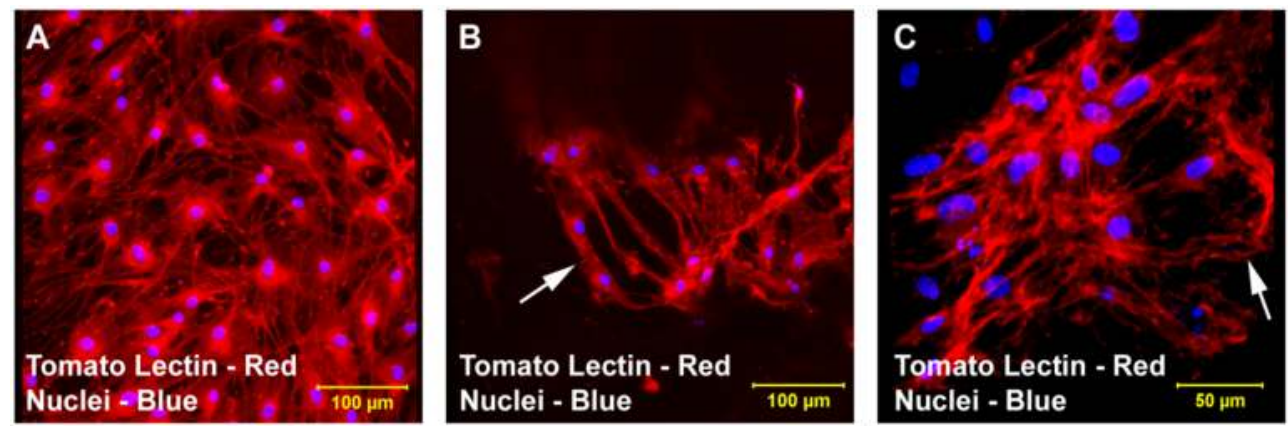

Figure 6. Localization of BMSCs derived endothelial cells by Texas Red labeled Lycopersicon Esculentum lectin/Tomato Lectin (LEL/TL) staining. BMSCs cultured in collagen-gel tubular scaffolds in both vasculogenic and non-vasculogenic culture conditions were incubated with tomato lectin (1:50 in $10 \mathrm{mM} \mathrm{N}$-2-hydroxyethylpiperazine- $\mathrm{N}^{\prime}$-2ethanesulfonic acid, $\mathrm{pH} 7.5 ; 0.15 \mathrm{M} \mathrm{NaCl}$ ), and was used to identify endothelial cells. Confocal laser scanning microscopic analysis of sections of day 14 tubular scaffolds in these media conditions demonstrated the typical cobblestone appearance of differentiating endothelial cells (A), fusion and self-assembly (B), and evolving primitive capillary plexus with attempted lumen formation (B-C, white arrows). Cells were also stained for nuclei (blue, DAPI). Image (A) shows a projection representing 19 sections collected at $5.05 \mu \mathrm{m}$ intervals $(90.90 \mu \mathrm{m})$. Image (B) shows a projection representing 13 sections collected at $4.05 \mu \mathrm{m}$ intervals $(48.60 \mu \mathrm{m})$. Image (C) shows a projection representing 15 sections collected at $6 \mu \mathrm{m}$ intervals $(84.00 \mu \mathrm{m})$. Merged images (A-C). (A-B, scale bar $100 \mu \mathrm{m}$; C, scale bar $50 \mu \mathrm{m})$.

To validate the findings of mRNA expression pattern of important vasculogenic markers in these tube cultures and to determine whether these messages were in fact translated into proteins, immunostaining of the BMSC tube culture was carried out (Figure 7 A-L; Figure 8 A-L). 

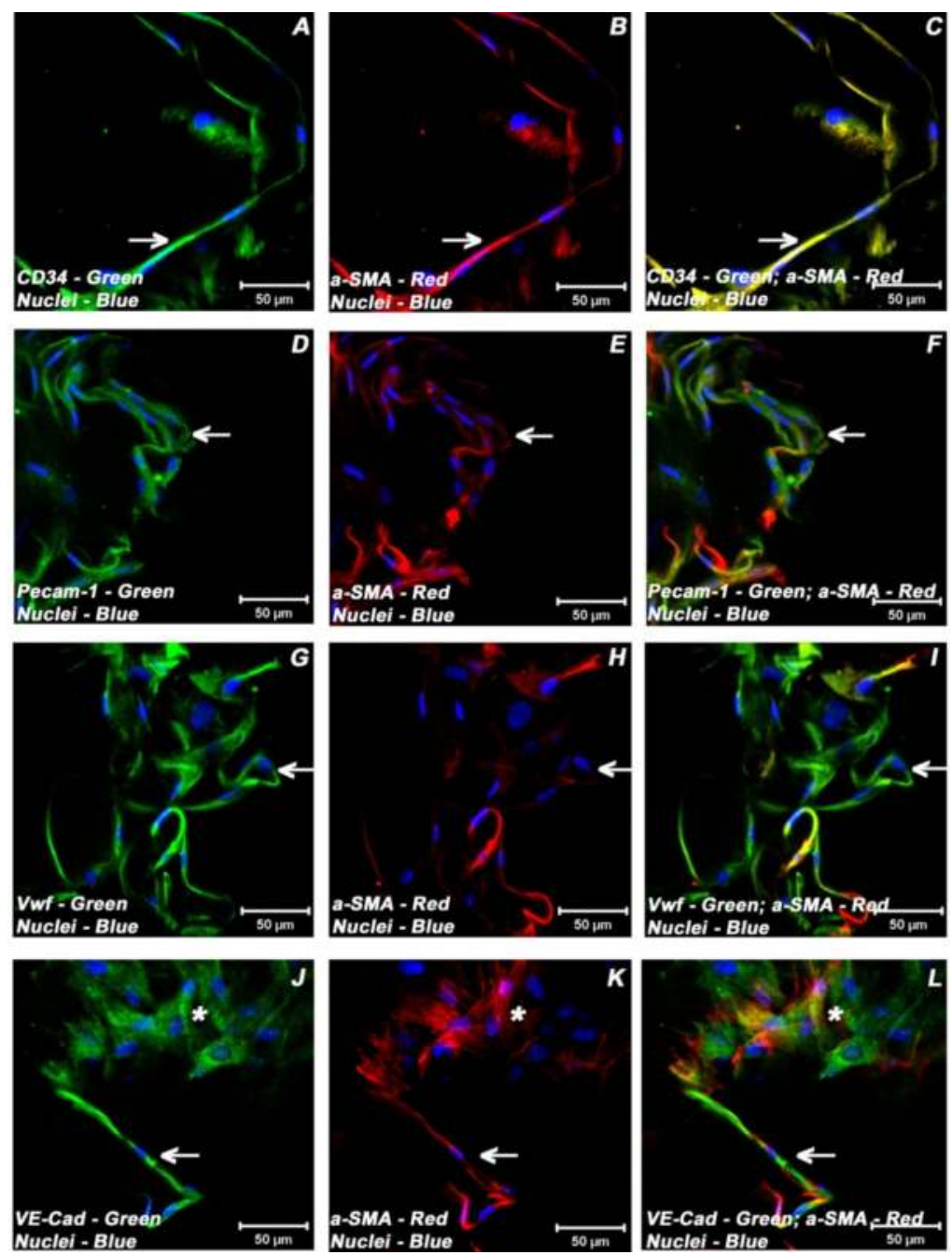

Figure 7. Expression pattern of various vasculogenic markers in tubular scaffold by confocal microscopy. Localization of key endothelial and smooth muscle cell phenotypic markers of day 21 non-vasculogenic tube cultures demonstrated the expression of CD34 (A-C), Pecam1 (D-F), Vwf (G-I), VE-cadherin (J-L) and a-SMA (B-C, E-F, H-I, K-L). Dual immunostainings of non-vasculogenic tube cultures (mesenchymal stem cell growth media, MSCGM) revealed areas of elongated and flattened cells composed of varying degrees of mature endothelial and smooth muscle cells (A-L). These cells were organized into a loose delicate network of nascent capillary-like structures composed of mature endothelial and smooth muscle cells and showed evidence of central lumen formation (white arrows, D-I). In addition, tube-like structures were emanating from the mixed population of vasculogenic cells represented by their distinct morphology and phenotypic expression (white arrows, A-C; white arrows, J-L). Cells were also stained for nuclei (blue, DAPI). Images (A-C) show a projection representing 15 sections collected at $5.05 \mu \mathrm{m}$ intervals $(70.70 \mu \mathrm{m})$. Images (D-F) show a projection representing 19 sections collected at $5.05 \mu \mathrm{m}$ intervals $(90.90 \mu \mathrm{m})$. Images $(\mathrm{J}-\mathrm{L})$ show a projection representing 19 sections collected at $4.04 \mu \mathrm{m}$ intervals $(72.90 \mu \mathrm{m})$. Merged images (A-L). (A-L, scale bar $50 \mu \mathrm{m})$. Adapted from Valarmathi et al., 2009. 

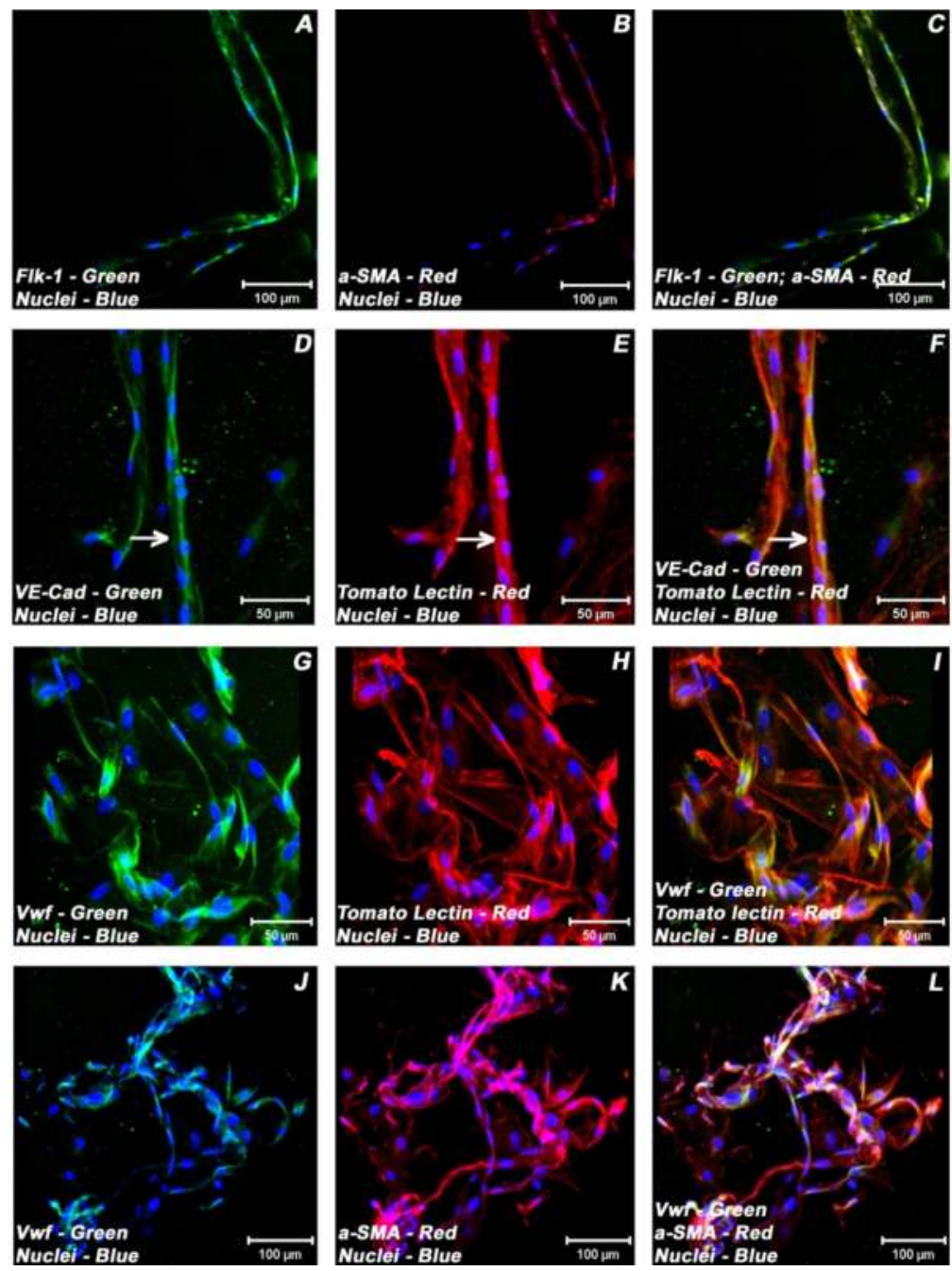

Figure 8. Expression pattern of various vasculogenic markers in tubular scaffold by confocal microscopy. Localization of key endothelial and smooth muscle cell phenotypic markers of day 21 vasculogenic tube cultures demonstrated the expression of Flk1 (A, C), VE-cadherin (D, F), Vwf $(G, I ; J, L)$, tomato lectin (E-F; H-I) and a-SMA (B-C, K-L). Dual immunostainings of vasculogenic tube cultures (microvascular endothelial growth medium, EGMMV) revealed areas of elongated cells composed of both mature endothelial and smooth muscle cells (A-L). These cells formed developing microvessl-like structures (A-F, J-L). The linear nascent capillary-like structures showed a translucent central lumen (white arrows, D-F). In addition, the cells were organized into a loose network of vascular cells and were in a ribbonlike configuration (G-I). These aligned vascular cells transformed into thin tube-like structures reminiscent of in vivo microvessel morphogenesis (J-L). Cells were also stained for nuclei (blue, DAPI). Images (D-F) show a projection representing 13 sections collected at $3.05 \mu \mathrm{m}$ intervals $(36.60 \mu \mathrm{m})$. Images (G-I) show a projection representing 18 sections collected at $7.05 \mu \mathrm{m}$ intervals $(119.8 \mu \mathrm{m})$. Images $(\mathrm{J}-\mathrm{L})$ show a projection representing 27 sections collected at $6.05 \mu \mathrm{m}$ intervals $(157.3 \mu \mathrm{m})$. Merged images (A-L). (A-C, J-L scale bar $100 \mu \mathrm{m}$; D-F, G-I scale bar $50 \mu \mathrm{m}$ ). Adapted from Valarmathi et al., 2009. 
It is well known that endothelial cells share a large majority of their characteristic antigenic markers with other types of hematopoietic and mesenchymal cells (Bertolini et al., 2006). Therefore, antigens such as CD31, CD34, CD144 (VE-cadherin), CD146, Vwf or CD105 are not only expressed by endothelial cells but also expressed by hematopoietic cells (specifically HSCs), platelets and certain subpopulations of fibroblasts. Hence to identify the differentiated and matured endothelial cells in the tubular scaffold a battery of various early and late stage vasculogenic markers such as Pecam1, CD34, Flt1, Flk1, VE-cadherin, fibronectin and Vwf were employed. In addition, tomato lectin, another marker specific for rat vascular endothelial cells, was found closely associated with Flk1 and Vwf staining. These endothelial associated markers localized to endothelial cell clusters and capillary-like structures that were present throughout the tubular construct. This suggests that BMSC-derived endothelial cells assembled into endothelium-lined tube-like structures and initiated the process of vasculogenesis, consistent with our previous report (Figure $9 \mathrm{~A}-\mathrm{H}$ ) (Valarmathi et al., 2008a). In addition, the BMSC-derived cells and the microvessel-like structures expressed the smooth muscle antigens, $\alpha$-SMA and calponin. These $\alpha$-SMA positive cells were recruited in juxtaposition to the tandemly arranged endothelial cells and, were attached and wrapped around in such a way that is reminiscent of in vivo microvessel morphogenesis.

In order to quantitate the degree of vasculogenesis, image morphometric analyses were used to determine the capillary density, vessel breadth and length (integrated morphometry subroutine of MetaMorph 6.1). In brief, confocal scanning laser microscopic color images were converted to 8-bit monochrome images for both image and fractal analysis (Fuseler et al., 2007; Fernandez et al., 2001; Grizzi et al., 2005; Valarmathi et al., 2012). The fluorescence vasculature in an image was defined as a Region of Interest (ROI) by being thresholded using the "set threshold" subroutine of MetaMorph Image analysis software (v.6.1). The morphological descriptors of fiber breadth were a representative measure of blood vessel diameter. Fiber length was measured using the integrated morphometry algorithm of MetaMorph. Using this technique we were able to reconfirm what our confocal images demonstrated. In microvascular media, the BMSC-derived microvessels were longer (63\%) and broader (37\%) when compared with microvessels generated in basal media (Figure 10).

Similarly, it is critically important to characterize the ultrastructural morphology of any stem cells that are directed to differentiate into vascular lineage cells. Scanning electron microscopic (SEM) analysis of the tubular constructs depicted the pattern of microvessel morphogenesis and maturity. These formed nascent capillary-like structures and elongated tube-like structures revealed patent lumen-like structures, elucidating the vessel-maturation (Figure 11). Besides, transmission electron microscopic (TEM) analysis (Hanaichi et al., 1986) revealed elongated capillary-like structures lined by differentiating endothelial cells (Figure 12A). These cells showed electron dense bodies as well as numerous small pinocytotic vesicles adjacent to the endothelial cell membranes as well as in their cytoplasm (Figure 12B, small black arrows). In addition these cells exhibited variously sized cell-cell junctions, which have the appearance of typical in vivo endothelial tight junctions (Figure 12C-F). 

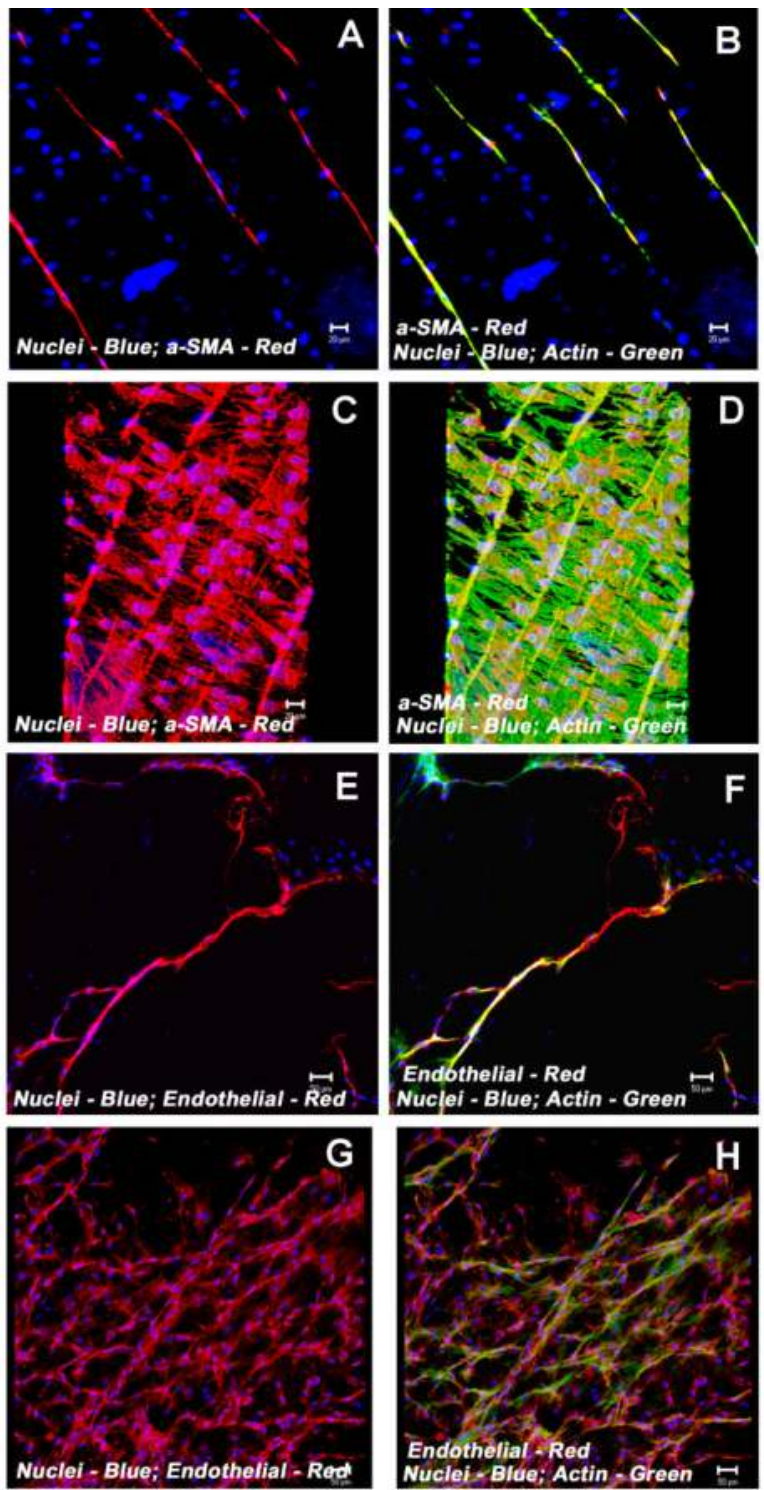

Figure 9. Expression pattern of vasculogenic markers a-SMA and tomato lectin (TL). Localization of BMSC-derived vascular progenitor cells on the collagen tube scaffold by confocal microscopy is seen in panels A, C, E, and G. The merged images showing the actin cytoskeleton are shown in panels $B, D, F$, and $H$. Sections of a day 9 osteogenic tube culture demonstrated nascent capillary-like structures positive for a-SMA (red, A). These elongated cord-like structures showed strong colocalization of a-SMA and actin (merged, B). In the tubes nuclei appeared aligned (blue, DAPI). In adjacent fields, abundant sheets of parallel oriented a-SMA positive cells were abutting the nascent vessel-like structures (red, C). The merged image (D) shows actin and a-SMA in vessel-like structures that appear to be in different planes with almost a perpendicular alignment with the underlying a-SMA positive cells (D). Similar sections of osteo- 
genic cultured tubes illustrate the sprouting and branching tubular structures positive for the rat endothelial marker tomato lectin (red, E-H). A plexus of arborizing endothelial cells was observed. These plexuses contained capillary-like vessels lined with endothelial cells (red, G). Similarly in the merged panel, the apparent multilayered nature of the vessels was observed. However in these fields, the plexuses of endothelial cells were not in a perpendicular arrangement but rather in a web-like orientation (merged, H). Figures $C$ and D were projections representing 19 sections collected at $2 \mu \mathrm{m}$ intervals. Figures $\mathrm{G}$ and $\mathrm{H}$ were projections representing 32 sections collected at $9 \mu \mathrm{m}$ intervals. Merged images (A-H) (A-D, Scale bar $20 \mu \mathrm{m}$; E-H, Scale bar $50 \mu \mathrm{m})$. Adapted from Valarmathi et al., 2008a.

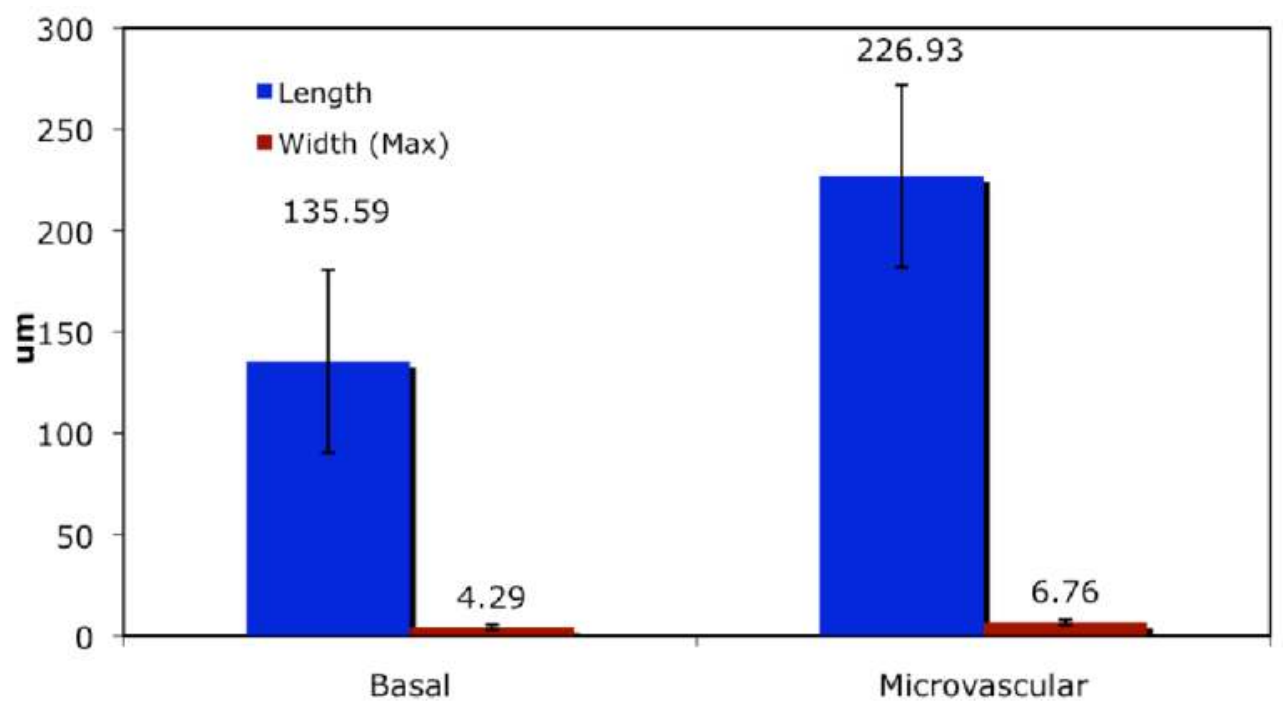

Figure 10. Morphometric analysis of microvessel-like structures generated in the walls of collagen-gel tubular constructs in different culture media, viz., basal or microvascular medium. 

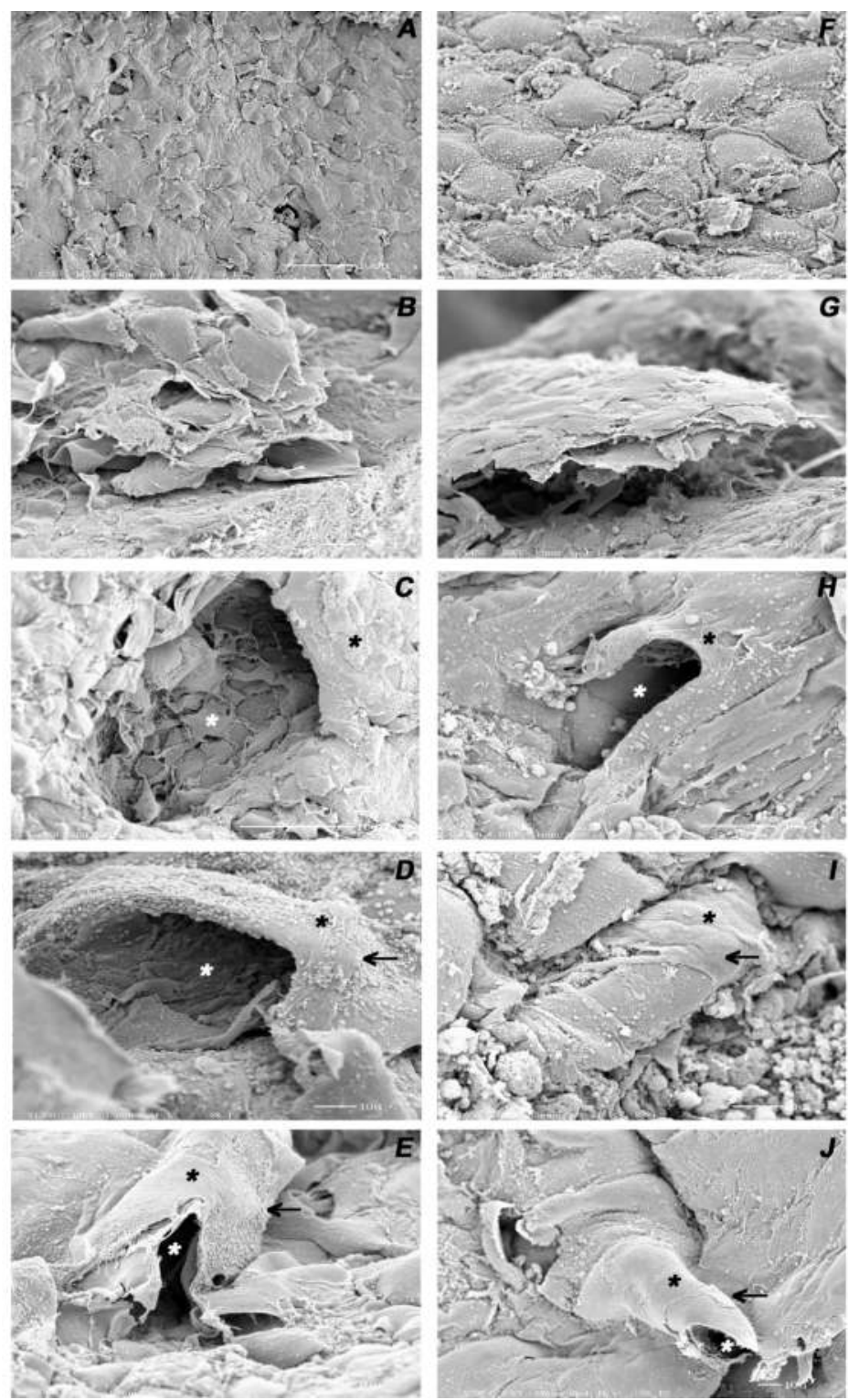

Figure 11. Scanning electron microscopic (SEM) analysis of tubular constructs. SEM analysis of day 28 tubular constructs under both vasculogenic and non-vasculogenic culture conditions showed the typical cobblestone appearance of differentiated endothelial cells $(A, F)$, stratification and networking $(B, G)$, and the presence of smooth-walled tubelike structures with its attached smooth muscle cells and/or pericytes (black arrows, D, E, I, J). Multiple smooth musclelike cells were wrapping around these tube-like structures (black asterisks, Figure $\mathrm{C}-\mathrm{E}, \mathrm{H}-\mathrm{J}$ ). These cylindrical structures revealed the presence of evolving patent lumens (white asterisks, C-E, H, J). Some of these luminal surfaces showed the regular cobblestone arrangement of endothelial cells (white asterisks, C, D). Adapted from Valarmathi et al., 2009. 

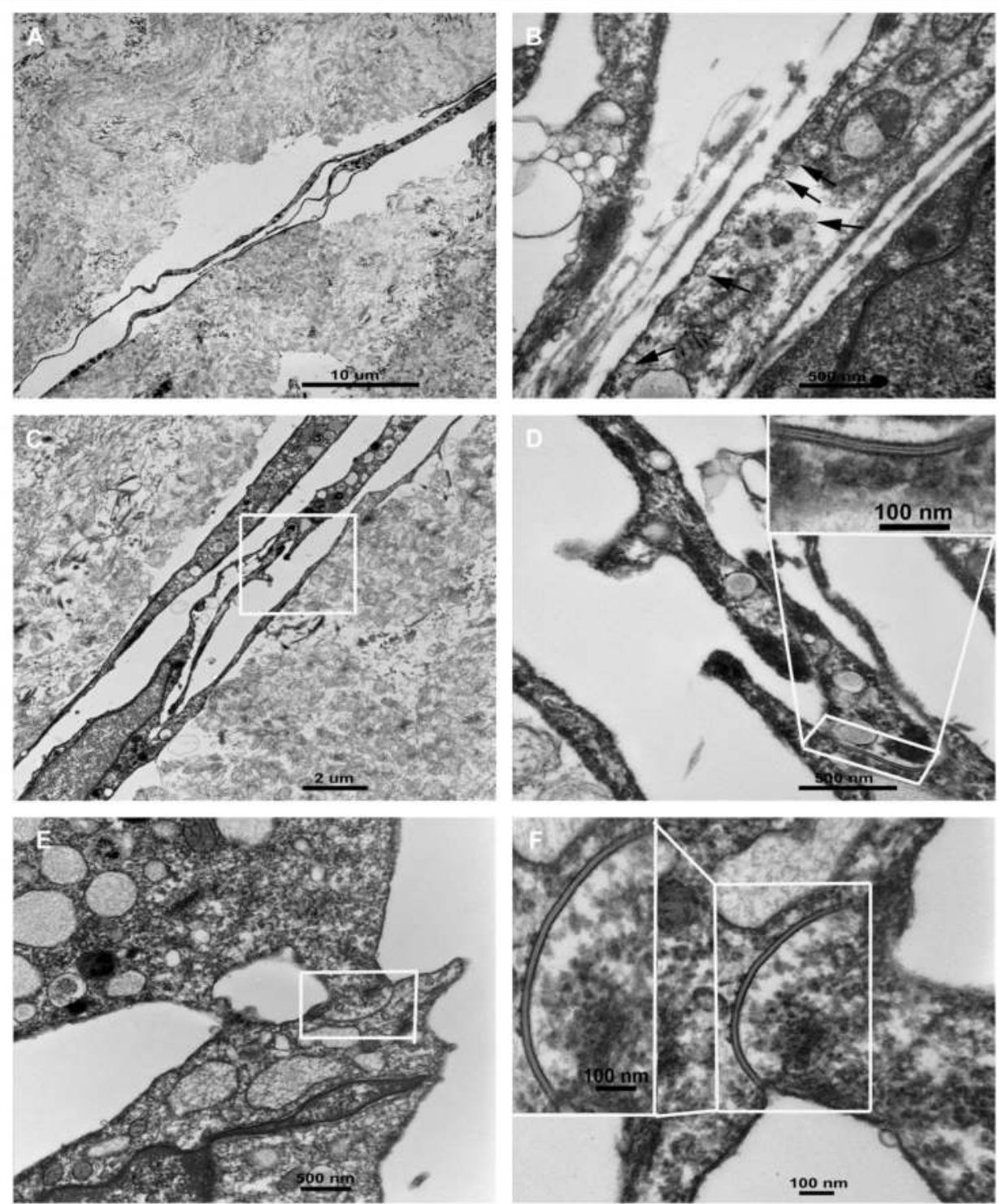

Figure 12. Transmission electron microscopic (TEM) analysis of tubular constructs. TEM analysis of day 28 tubular constructs under both vasculogenic and non-vasculogenic culture conditions showed a vessel-like structure containing many small dense bodies within endothelial cells on either side of the lumen (A). Note the most obvious feature of endothelial cells, the concentration of small vesicles (pinocytotic vesicles) adjacent to the endothelial cell membranes ( $B$, black arrows). The interdigitating endothelial cells showing junctional regions ( $C, E$, inserts, lower magnification). The typical adherent junction could be visualized between two overlapping endothelial cell processes ( $D$, $F$, inserts, higher magnification). 
Furthermore, the ability to identify endothelial cells based on their increased metabolism of Ac-LDL was examined using Ac-LDL tagged with the fluorescent probe (Dil-Ac-LDL) (Voyta et al., 1984). BMSC-derived endothelial cells and the nascent capillary-like structures were brilliantly fluorescent whereas the fluorescent intensity of smooth muscle cells/pericytes was barely detectable as reported previously (Valarmathi et al., 2009). This suggests that the formed endothelial cells were not only fully differentiated but also functionally competent and matured (Figure 13A-J).

This behavior of BMSCs and their exhibition of vasculogenic differentiation potential can be attributed to the nature of microenvironmental factors in this culture conditions. The preconditioned factors in the growth microenvironment rendered by the aligned type I collagen fibers of the tubular scaffold and the soluble differentiating factors provided by the vasculogenic and non-vasculogenic media may be behind the BMSC fate determination. Further work is ongoing to determine whether our prevascularised tubular scaffolds can survive implantation into a tissue defect and is able to anastomose promptly with vascular sprouts emanating from the host. Finally, our morphological, molecular, immunological and biochemical data reveal the intrinsic vasculogenic differentiation potential of BMSCs under appropriate 3-D environmental conditions.

Previously, it has been shown that mature vascular endothelium can give rise to smooth muscle cell (SMC) via endothelial-mesenchymal transdifferentiation, coexpressing both endothelial and SMC-specific phenotypic markers (Frid et al., 2002). Recently, it has been show that Flk1-expressing blast cells derived from embryonic stem cells can act as precursors that can differentiate into both endothelial and mural cell populations of the vasculature (Yamashita et al., 2000). In this study, clonal analyses revealed the bi-lineage potential of BMSCs, suggesting that both endothelial and smooth muscle/pericytes could be derived from single colonies. However, in general, BMSC-derived colonies are clonal or nearly clonal. The colonies of BMSCs resultant from a number of cells may represent co-existence of several subclones, each capable of differentiating into specific lineages. Hence, single cell-derived colonies that are stably transfected with lineage specific markers are needed to gain more meaningful insights and address the origin of both lineages.

Our results indicate that the 3-D tubular scaffold with its unique characteristics provides a favorable microenvironment that permits the development of in situ microvascular structures. Moreover, this is the first ever documentation that explicitly demonstrates that adult BMSCs under appropriate in vitro environmental cues can be induced to undergo vasculogenic differentiation culminating in microvessel morphogenesis. Our model recapitulates many aspects of in vivo de novo vasculogenesis. Thus, this unique culture system provides an in vitro model to investigate the maturation and differentiation of BMSC-derived vascular endothelial and smooth muscle cells in the context of postnatal vasculogenesis. In addition, it allows us to elucidate various molecular mechanisms underlying the origin of both endothelial and smooth muscle cells and especially to gain a deeper insight and validate the emerging concept of 'one cell and two fates' hypothesis of vascular development (Yamashita et al., 2000). 

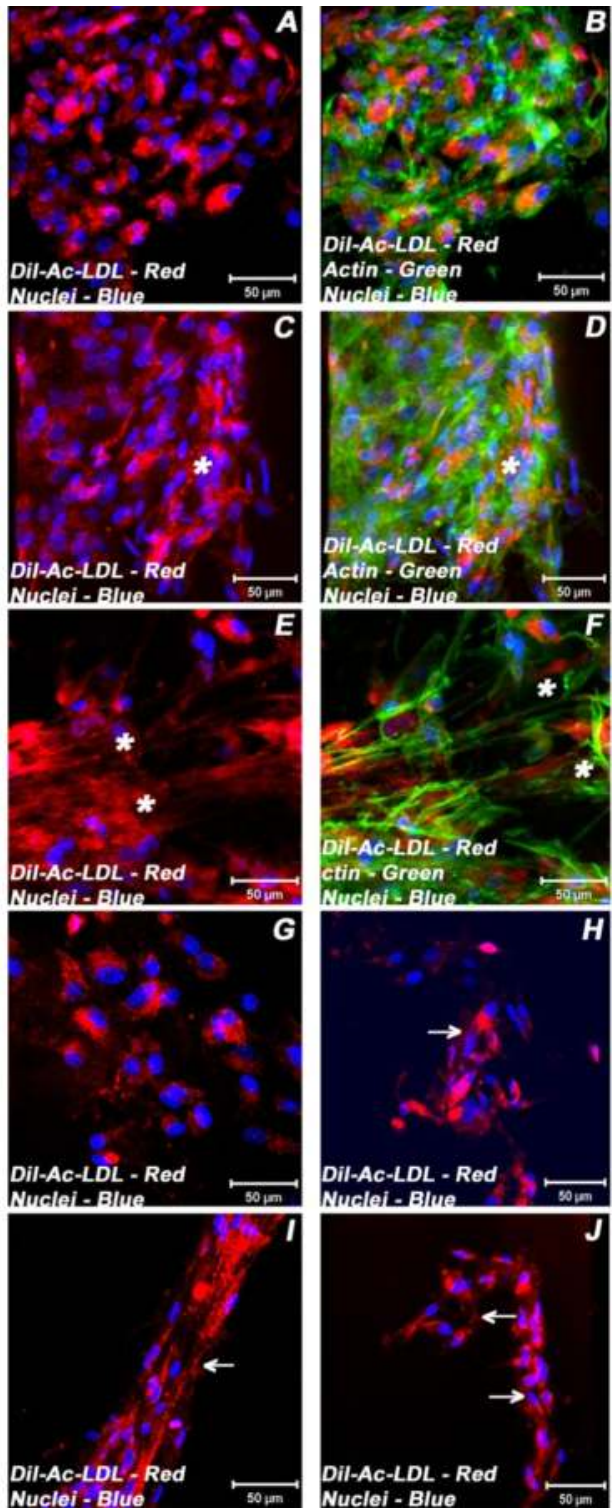

Figure 13. Characterization of BMSC-derived endothelial cells by Dil-Ac-LDL uptake. BMSCs cultured in collagen-gel tubular scaffolds in non-vasculogenic (mesenchymal stem cell growth medium, MSCGM) and vasculogenic (microvascular endothelial cell growth medium, EGMMV) culture conditions were incubated with $10 \mu \mathrm{g} / \mathrm{ml}$ of Dil-Ac-LDL for 4 to 6 hours. Confocal laser scanning microscopic analysis of sections of day 21 tubular scaffolds in MSC growth medium revealed abundant punctate perinuclear bright red fluorescence of the differentiated and matured endothelial cells (A-F). These labeled vascular cells were organized into a discrete cluster (A, B), assembled into tangled capillary-like structures on top of a cluster (white asterisks, C, D) and, transformed into nascent linear and branching capillary-like structures (white asterisks, E, F). Similarly, confocal laser scanning microscopic analysis of sections of day 21 tubular 
scaffolds in microvascular endothelial cell growth medium revealed typical abundant punctate perinuclear bright red fluorescence of the differentiated and matured endothelial cells (G-J). These labeled vascular cells were organized into small discrete clusters $(G)$, self-organized into numerous small capillaries with a central lumen (white arrow, H), assembled into solid cord of cells (white arrow, I) and, transformed into tube-like structure with attempted lumen formation (white arrows, J). Cells were also stained for nuclei (blue, DAPI) and fibrillar actin (green, Alexa ${ }^{\circledR} 488$ phalloidin). Images (A-B) show a projection representing 13 sections collected at $3.05 \mu \mathrm{m}$ intervals $(36.60 \mu \mathrm{m})$. Images (C-D) show a projection representing 20 sections collected at $4.05 \mu \mathrm{m}$ intervals $(76.95 \mu \mathrm{m})$. Images (E-F) show a projection representing 4 sections collected at $2.05 \mu \mathrm{m}$ intervals $(6.15 \mu \mathrm{m})$. Image $(\mathrm{H})$ shows a projection representing 20 sections collected at $5 \mu \mathrm{m}$ intervals $(95.00 \mu \mathrm{m})$. Image (I) shows a projection representing 13 sections collected at $4 \mu \mathrm{m}$ intervals $(48.00 \mu \mathrm{m})$. Image $(J)$ shows a projection representing 22 sections collected at $5 \mu \mathrm{m}$ intervals $(105.00 \mu \mathrm{m})$. Merged images (A-J). (A-J, scale bar $50 \mu \mathrm{m})$. Adapted from Valarmathi et al., 2009.

\section{Conclusions}

Here we report a unique 3-D culture system that recapitulates many aspects of postnatal de novo vasculogenesis and angiogenesis. This is the first comprehensive report that evidently demonstrates that BMSCs under appropriate in vitro environmental conditions can be induced to undergo vasculogenic differentiation culminating in microvessels. Since BMSCs differentiated into both endothelial and smooth muscle cell lineages, this in vitro model system provides a tool for investigating the cellular and molecular origin of both vascular endothelial cells and smooth muscle cells. In addition, this system can potentially be harnessed to develop in vitro engineering of microvascular trees, especially using autologous bonemarrow-derived BMSCs for therapeutic purposes in regenerative medicine.

\section{Acknowledgements}

"This work was supported by an award from the American Heart Association." - National Scientist Development Grant (11SDG5280022) as well "This material is based upon work supported by the National Science Foundation/EPSCoR under Grant No. (EPS - 0903795)." The South Carolina Project for Organ Biofabrication, for Valarmathi Thiruvanamalai.

\section{Author details}

Mani T. Valarmathi", Stefanie V. Biechler and John W. Fuseler

*Address all correspondence to: valarmathi.thiruvanamalai@uscmed.sc.edu or valarmathi64@hotmail.com

Laboratory of Stem Cell Biology and Tissue Engineering, Department of Cell Biology and Anatomy, School of Medicine, University of South Carolina, Columbia, South Carolina, USA 


\section{References}

[1] Aggarwal S and Pittenger MF. Human mesenchymal stem cells modulate allogeneic immune cell responses. Blood 2005;105:1815-1822.

[2] Albelda SM, Muller WA, Buck CA, Newman PJ. Molecular and cellular properties of PECAM-1 (endoCAM/CD31): a novel vascular cell-cell adhesion molecule. J Cell Biol 1991;114:1059-68.

[3] Al-Khaldi A, Eliopoulos N, Martineau D, Lejeune L, Lachapelle K, Galipeau J. Postnatal bone marrow stromal cells elicit a potent VEGF-dependent neoangiogenic response in vivo. Gene Ther 2003;10:621-29.

[4] Anokhina EB, Buravkova LB. Heterogenecity of stromal cell precursers isolated from rat bone marrow. Cell and Tissue Biology 2007;1:1-7. (Original article in Russian Tsitologiya 2007;49:40-47.)

[5] Bautch VL, Redick SD, Scalaia A, Harmaty M, Carmeliet P, Rapoport R. Characterization of the vasculogenic block in the absence of vascular endothelial growth factorA. Blood 2000;95:1979-87.

[6] Bertolini F, Shaked Y, Mancuso P, Kerbel RS. The multifaceted circulating endothelial cell in cancer: towards marker and target identification. Nat Rev Cancer 2006;6:835-45.

[7] Bianco P, Riminucci M, Gronthos S, Robey PG. Bone marrow stromal stem cells: nature, biology, and potential applications. Stem Cells 2001;19:180-92.

[8] Brey EM, Uriel S, Greisler HP, Patrick Jr. CW, McIntire LV. Therapeutic neovascularization: contributions from bioengineering. Tissue Eng 2005;11:567-84.

[9] Carlson BM. Tissue engineering and regeneration In: ed. Principles of regenerative biology. Amsterdam: Elsevier, 2007; pp259-278.

[10] Carmeliet P, Jain RK. Angiogenesis in cancer and other diseases. Nature 2000;407:249-257.

[11] Carmeliet P, Luttun A. The emerging role of the bone marrow-derived stem cells in (therapeutic) angiogenesis. Thromb Haemost 2001;86:289-97.

[12] Carmeliet P. Mechanisms of angiogenesis and arteriogenesis. Nat Med 2000;6:389-95.

[13] De Palma M, Venneri MA, Galli R, Sergi SL, Politi LS, Sampaolesi M, et al. Tie2 identifies a hematopoietic lineage of proangiogenic monocytes required for tumor vessel formation and a mesenchymal population of pericytes progenitors. Cancer Cell $2005 ; 8: 211-226$.

[14] Dominici M, Le Blanc K, Mueller I, Slaper-Cortenback I, Marini F, Krause D, et al. Minimal criteria for defining multipotent mesenchymal stromal cells. The International Society For Cellular Therapy position statement. Cytotherapy 2006;8:315-7. 
[15] Even-Ram S, Yamada KM. Cell migration in 3D matrix. Curr Opin Cell Biol 2005;17:524-32.

[16] Fernández E, Jelinek HF. 2001. Use of fractal theory in neuroscience: methods, advantages, and potential problems. Methods. 2001;24:309-21.

[17] Folkman J, Haudenschild C. Angiogenesis in vitro. Nature 1980;288:551-56.

[18] Frid MG, Kale VA, Stenmark KR. Mature vascular endothelium can give rise to smooth muscle cells via endothelial-mesenchymal transdifferentiation: in vitro analysis. Circ Res 2002;90:1189-96.

[19] Fukuda K. Development of regenerative cardiomyocytes from mesenchymal stem cells for cardiovascular tissue engineering. Artif Organs 2001;25:187-193.

[20] Fuseler JW, Millette CF, Davis JM, Carver W. Fractal and image analysis of morphological changes in the actin cytoskeleton of neonatal cardiac fibroblasts in response to mechanical stretch. Microsc Microanal. 2007;3:133-43.

[21] Fuseler JW, Valarmathi MT. Modulation of the migration and differentiation potential of adult bone marrow stromal stem cells by nitric oxide. Biomaterials 2012;33:1032-43.

[22] Grizzi F, Russo C, Colombo P, Franceschini B, Frezza EE, Cobos E, et al. Quantitative evaluation and modeling of two-dimensional neovascular network complexity: the surface fractal dimension. BMC Cancer. 2005;5:14-23.

[23] Hanaichi T, Sato T, Iwamoto T, Malavasi-Yamashiro J, Hoshino M, Mizuno N. A stable lead by modification of Sato's method. J Electron Microsc (Tokyo). 1986;35:304-06.

[24] His W. Lecithoblast und Angioblast der Wirbeltiere. Abhandl Math-Phys Ges Wiss 1900;26:171-328.

[25] Ingber DE, Folkman J. How does extracellular matrix control capillary morphogenesis? Cell 1989;58:803-05.

[26] Ingber DE, Folkman J. Mechanochemical switching between growth and differentiation during fibroblast growth factor-stimulated angiogenesis in vitro: Role of extracellular matrix. J Cell Biol 1989;109:317-30.

[27] Kinnaird T, Stabile E, Burnett MS, Shou M, Lee CW, Barr S, et al. Local delivery of marrow-derived stromal cells augments collateral perfusion through paracrine mechanisms. Circulation 2004;109:1543-49.

[28] Kleinman HK, McGarvey ML, Liotta LA, Robey PG, Tryggvason K, Martin GR. Isolation and characterization of type IV procollagen, laminin, and heparan sulfate proteoglycan from the EHS sarcoma. Biochemistry 1982;21:6188-93.

[29] Lanza RP, Langer R, Vacanti J. Principles of tissue engineering. San Diego, CA: Academic Press; 2000. 
[30] Levenberg S. Engineering blood vessels from stem cells: recent advances and applications. Curr Opin Biotechnol 2005;16:516-23.

[31] Madri JA, Pratt BM, Tucker AM. Phenotypic modulation of endothelial cells by transforming growth factor- depends upon the composition and organization of the extracellular matrix. J Cell Biol 1988;106:1375-84.

[32] Makino S, Fukuda K, Miyoshi S, Konishi F, Kodama H, Pan J, et al. Cardiomyocytes can be generated from marrow stromal cells in vitro. J Clin Invest 1999;103:697-705.

[33] Montesano R, Orci L, Vassalli JD. In vitro rapid organization of endothelial cells into capillary-like network is promoted by collagen matrices. J Cell Biol 1983;97:1648-52.

[34] Oswald J, Boxberger S, Jorgensen B, Feldmann S, Ehninger G, Bornhauser M, et al. Mesenchymal stem cells can be differentiated into endothelial cells in vitro. Stem Cells 2004;22:377-84.

[35] Pfaffl MW, Horgan GW, Dempfle L. Relative expression software tool (REST) for group-wise comparison and statistical analysis of relative expression results in realtime PCR. Nucleic Acids Res 2002;30:e36.

[36] Pfaffl MW. A new mathematical model for relative quantification in real-time RTPCR. Nucleic Acids Res 2001;29:e45.

[37] Pittenger MF, Mackay AM, Beck SC, Jaiswal RK, Douglas R, Mosca JD, et al. Multilineage potential of adult human mesenchymal stem cells. Science 1999;284:143-147.

[38] Prater DN, Case J, Ingram DA, Yoder MC. Working hypothesis to redefine endothelial progenitor cells. Leukemia 2007;21:1141-49.

[39] Reyes M, Dudek A, Jahagirdar B, Koodie L, Marker PH, Verfaillie CM. Origin of endothelial progenitors in human postnatal bone marrow. J Clin Invest 2002;109:337-46.

[40] Risau W, Flamme I. Vasculogenesis. Annu Rev Cell Dev Biol 1995;11:73-91.

[41] Rozen S, Skaletsky HJ. Primer3 on the WWW for general users and for biologist programmers. In: Krawetz S, Misener S (eds) Bioinformatics Methods and Protocols: Methods in Molecular Biology. Humana Press, Totowa, NJ, 2000; pp 365-386.

[42] Shalaby F, Ho J, Stanford WL, Fischer K-D, Schuh AC, Schwartz L, et al. A requirement for Flk-1 in primitive and definitive hematopoiesis and vasculogenesis. Cell 1997;89:981-90.

[43] Urbich C, Dimmeler S. Endothelial progenitor cells functional characterization. Trends Cardiovasc Med 2004;14:318-22.

[44] Vailhe B, Vittet D, Feige JJ. In vitro models of vasculogenesis and angiogenesis. Lab Invest 2001;81:439-52.

[45] Valarmathi MT, Davis JM, Yost MJ, Goodwin RL, Potts JD. A three-dimensional model of vasculogenesis. Biomaterials 2009;30:1098-112. 
[46] Valarmathi MT, Fuseler JW, Goodwin RL, Davis JM, Potts JD. The mechanical coupling of adult marrow stromal stem cells during cardiac regeneration assessed in a 2D co-culture model. Biomaterials 2011;32:2834-50.

[47] Valarmathi MT, Goodwin RL, Fuseler JW, Davis JM, Yost MJ, Potts JD. A 3-D cardiac muscle construct for exploring adult marrow stem cell based myocardial regeneration. Biomaterials 2010;31:3185-200.

[48] Valarmathi MT, Yost MJ, Goodwin RL, Potts JD. A three-dimensional tubular scaffold that modulates the osteogenic and vasculogenic differentiation of rat bone marrow stromal cells. Tissue Eng 2008a;14:491-504.

[49] Valarmathi MT, Yost MJ, Goodwin RL, Potts JD. The influence of proepicardial cells on the osteogenic potential of marrow stromal cells in a three-dimensional tubular scaffold. Biomaterials 2008b;29:2203-16.

[50] Voyta JC, Via DP, Butterfield CE, Zetter BR. Identification and isolation of endothelial cells based on their increased uptake of acetylated-low density lipoprotein. 1984;6:2034-2040.

[51] Wakitani S, Saito T, Caplan AI. Myogenic cells derived from rat bone marrow mesenchymal stem cells exposed to 5-azacytidine. Muscle Nerve 1995;18:1417-26.

[52] Yamashita J, Itoh H, Hirashima M, Ogawa M, Nishikawa S, Yurugi T, et al. Flk1-positive cells derived from embryonic stem cells serve as vascular progenitors. Nature 2000;408:92-96.

[53] Yost MJ, Baicu CF, Stonerock CE, Goodwin RL, Price RL, Davis M, et al. A novel tubular scaffold for cardiovascular tissue engineering. Tissue Eng 2004;10:273-84. 
